\title{
Abrupt upper-plate tilting during slab-transition-zone collision
}

\author{
Fabio Crameri ${ }^{1}$, Carolina Lithgow-Bertelloni ${ }^{2}$ \\ ${ }^{1}$ Centre for Earth Evolution and Dynamics (CEED), University of Oslo, Postbox 1028 \\ Blindern, 0315 Oslo, Norway \\ ${ }^{2}$ Department of Earth Sciences, University College London, Gower Street, London \\ WC1E 6BT, United Kingdom
}

\begin{abstract}
The sinking remnant of a surface plate crosses and interacts with multiple boundaries in Earth's interior. Here, we specifically investigate the prominent dynamic interaction of the sinking plate portion with the upper-mantle transition zone and its corresponding surface elevation signal. We unravel, for the first time, that the collision of the sinking slab with the transition zone induces a sudden, dramatic downward tilt of the upper plate towards the subduction trench. Unraveling this crucial interaction was only possible thanks to state-of-the-art numerical modelling and post-processing. The new model that is introduced here to study the dynamically self-consistent temporal evolution of subduction features accurate subduction-zone topography, robust single-sided plate sinking, stronger plates close to laboratory values, an upper-mantle phase transition, and simple continents at a free surface. To distinguish the impact of the new physical model features, three different setups are used: The simplest model setup includes a basic highviscosity lower mantle, the second adds a $660-\mathrm{km}$ phase transition, and the third includes, additionally, a continental upper plate. Common to all models is the clear topographic signal upon slab-transition-zone interaction: The upper plate tilts abruptly towards the subduction trench by about 0.05 degrees and over around $10 \mathrm{Ma}$. This dramatic increase in upper-plate tilt can be related to the slab-induced excitation of the high-viscosity lower mantle, which introduces a wider flow pattern. A large change in horizontal extent of inundation of up to $900 \mathrm{~km}$ is observed as a direct consequence of the upperplate tilting. Such an abrupt variation in surface topography and inundation extent should be clearly visible in temporal records of large-scale surface el-
\end{abstract}


evation and might explain continental tilting as observed in Australia since the Eocene and North America during the Phanerozoic.

Keywords: Upper-Plate Tilt, Upper-Mantle Transition Zone, Subduction Dynamics, Surface Topography, Numerical Modelling

\section{Introduction}

Most of the fascinating complexity of subduction zones arises from the variable physical and rheological state of the colliding plates and their interaction with the surrounding mantle. The rheology of the mantle plays as big a role as subducting-plate size, rheology, age and speed. Individual subduction zones can therefore not be fully described by just one single physical complexity, but need to be rather characterised by many: Plate age and speed, trench movement, surface topography, the subducting-plate's stress state and its geometry in the upper-mantle are commonly used (Jarrard, 1986; Lallemand et al., 2005). Moreover, the transition zone from the upper mantle (UM) to the lower mantle (LM) directly affects a subducting plate: Some sinking slabs appear to directly penetrate the transition zone and continue sinking into the lower mantle, while others initially stagnate vertically above the transition zone (van der Hilst et al., 1991; Li and Romanowicz, 1996; Bijwaard et al., 1998; Grand, 2002; Fukao and Obayashi, 2013; Goes et al., 2017).

This $660-\mathrm{km}$ discontinuity, where some slabs appear to stagnate, is attributed to the phase transition from ringwoodite to bridgmanite and ferropericlase (e.g., Bina, 1991). It is accompanied by a viscosity jump of a factor 10-100 (Hager, 1984; Hager and Richards, 1989; King and Masters, 1992; Ricard et al., 1993; Forte and Mitrovica, 1996) and a density increase by $10^{2}-10^{3} \mathrm{~kg} \mathrm{~m}^{-3}$, both of which hamper slab sinking. The physics of slab-transition-zone interaction has been studied extensively for slab tongue deformation (Ribe et al., 2007; Běhounková and Čížková, 2008; Ribe, 2010; Stegman et al., 2010; Lee and King, 2011; Li and Ribe, 2012), slab stagnation and trench retreat rates (Kincaid and Olson, 1987; Griffiths et al., 1995; Zhong and Gurnis, 1995; Christensen, 1996; Zhong and Gurnis, 1997; Funiciello et al., 2003, Cížková and Bina, 2013; Garel et al., 2014; Agrusta et al., 2014, 2017). These studies suggest that a slab's propensity for penetrating into the lower mantle decreases for low impinging angle of the slab at the transition zone (Kincaid and Olson, 1987), low negative slab buoyancy, and 
high overriding-plate and hence trench mobility (Zhong and Gurnis, 1995; Christensen, 1996; Zhong and Gurnis, 1997). The metastability of pyroxene in cold slab cores might additionally prevent the slab from entering the lower mantle (Agrusta et al. 2014).

Despite this large effort to understand the dynamic interaction of the sinking plate with the upper-mantle (UM) transition zone, no study focused on the direct link between the slab-transition-zone impact and surface topography. Yet, surface topography is the most direct observable we have on deep mantle dynamics. Many studies focused, however, on the apparent topographic impact general subduction has on the upper plate (e.g., Mitrovica et al., 1989; Gurnis, 1992; Zhong and Gurnis, 1994; Dávila et al., 2010; Duretz et al., 2011; Eakin et al., 2014; Crameri et al., 2017). The initiation of subduction and its general subsequent evolution have, for example, been ascribed to cause significant dynamic subsidence of continental upper plates in the form of a tilt towards the subduction trench Gurnis, 1992; LithgowBertelloni and Gurnis, 1997). This interplay is, for example, used to roughly explain the sedimentary accumulation along the convergent plate boundary of Northern America during the Phanerozoic (Mitrovica et al., 1989) or on the Australian continent during the Cenozoic (Russell and Gurnis, 1994; Sandiford, 2007; DiCaprio et al., 2009; Heine et al., 2010).

Crameri et al. (2017) shows that elevation changes of the upper plate are mostly controlled by slab-dip angle and slab buoyancy, but crucially, also by radial mantle viscosity. Here, we focus therefore on the latter, on the radial mantle viscosity and its topographic control through altering subductioninduced flow. To do so, we use an improved version of the time-dependent and global mantle convection model with self-consistent single-sided subduction (e.g., Crameri and Tackley, 2015). Previous modelling studies have outlined ways to enable mantle convection with mobile plates (e.g., Gurnis, 1988; Trompert and Hansen, 1998; Moresi and Solomatov, 1998; Tackley, 2000; Zhong et al., 2000). Our model is naturally based on these, but also, and more specifically, on previous developments that enabled modelling the interaction of deep mantle dynamics with surface topography (e.g., Mitrovica et al., 1989). Our model is time-dependent, has a free surface, and a weak subduction fault to allow a more realistic, asymmetric surface topography (Zhong and Gurnis, 1995; Funiciello et al., 2003). It employs a strongly non-linear rheology (e.g., Č́ž́ková and Bina, 2013; Agrusta et al., 2017) and lateral viscosity gradients to reproduce surface topography more-realistically (Gérault et al., 2015; Taramón et al. 2015), and is calculated in high reso- 
lution to reproduce subduction dynamics and surface topography accurately (e.g., Garel et al., 2014). In addition, our model incorporates the whole mantle depth, is dynamically fully self-consistent, and the weak crustal layer is produced and subducted freely instead of being imposed Crameri et al. (2017).

In this study, we introduce even further improvements to enable a model with more realistic (i.e., closer to laboratory values) yielding parameters, a higher Rayleigh number of the flow, more accurate subduction-zone topography, and the addition of both an upper-mantle phase transition and, crucially, floating continents.

\section{Methods}

We use here a state-of-the-art numerical model of global mantle convection with self-consistent single-sided subduction (Crameri and Tackley, 2015). For this study, we use an improved version of the geodynamic model introduced in Crameri et al. (2017). The detailed physical and numerical aspects of the model as well as the fully-automated diagnostics of the postprocessing and additional methodology are described below.

\subsection{Physical Model}

We model a visco-plastic, incompressible mantle under the Boussinesq approximation, for which the relevant non-dimensional equations for conservation of mass, momentum and energy are given by

$$
\begin{gathered}
\vec{\nabla} \cdot \vec{v}=0 \\
\vec{\nabla} \cdot \sigma_{i j}-\vec{\nabla} p=\operatorname{RaT} \hat{\vec{e}}_{z} \\
\frac{\partial T}{\partial t}=\nabla^{2} T-\vec{v} \cdot \vec{\nabla} T+H
\end{gathered}
$$

where $v$ is the velocity, $\sigma_{i j}$ is the deviatoric stress tensor, $p$ the pressure, $T$ the temperature, $\overrightarrow{\vec{e}}_{z}$ the vertical unit vector, $t$ the time and $H$ the nondimensional internal heating rate. The temperature-based Rayleigh number $(R a)$ can be expressed in terms of density $(\rho)$, gravitational acceleration $(g)$, temperature scale $(\Delta T)$, mantle depth $(D)$, thermal diffusivity $(\kappa)$ and reference viscosity $\left(\eta_{0}\right)$ as 


$$
R a=\frac{\rho g \alpha \Delta T D^{3}}{\eta_{0} \kappa}
$$

The applied temperature-based Rayleigh number is $10^{7}$ and the nondimensional internal heating rate is 20.0, which gives an internal heatingbased Rayleigh number of $2.0 \times 10^{8}$. The assumed rheology is strongly temperature- and pressure-dependent:

$$
\eta(T, p)=\eta_{A} \cdot \exp \left[\frac{E_{a c t}+p V_{a c t}}{R T}\right]
$$

where $\eta$ is the viscosity, $p$ is the pressure, $R=8.314 \mathrm{~J} \mathrm{~mol}^{-1} \mathrm{~K}^{-1}$ is the gas constant, $T$ the temperature, $E_{\text {act }}$ the activation energy, $V_{a c t}$ the activation volume and $\eta_{A}$ is set such that $\eta$ gives the reference viscosity $\left(\eta_{0}\right)$ at $T=1600 \mathrm{~K}$ and $p=0 \mathrm{~Pa}$ (see Table 1 for the detailed model parameters). Additionally, plastic yielding is included by a yield stress limiter using a Drucker-Prager yield criterion with the pressure-dependent yield stress $\sigma_{y, b r i t t l e}$ based on Byerlee's law

$$
\sigma_{y, b r i t t l e}=C+p \mu
$$

with specified friction coefficient $\mu$ and cohesion $C$. We additionally apply a maximum, ductile yield stress given by

$$
\sigma_{y, \text { ductile }}=\sigma_{y, \text { const }}+\Delta \sigma_{y} \cdot d
$$

where $\sigma_{y, c o n s t}$ is the surface value of the ductile yield stress, $\Delta \sigma_{y}$ is the ductile yield stress gradient and $d$ is the non-dimensional depth ranging from 0 (top) to 1 (bottom). The effective yield stress is then given by

$$
\sigma_{y}=\min \left[\sigma_{y, b r i t t l e}, \sigma_{y, d u c t i l e}\right]
$$

with a cross-over depth between brittle and ductile yielding at approximately half the lithosphere depth (i.e., here $72 \mathrm{~km}$ ). Models with an uppermantle transition zone apply different diffusion- and dislocation-creep parameters to the upper- and lower mantle (see Table 2).

If plastic yielding occurs, the effective viscosity on the corresponding grid points becomes $\eta_{e f f}=\min \left[\eta(T, p), \eta_{y}\right]$ with $\eta_{y}=\sigma_{y} /(2 \dot{\epsilon})$. Finally, the viscosity variation is limited to 9 orders of magnitude by applying an upper and lower cutoff of $\eta_{\max }=10^{5} \eta_{0}$ and $\eta_{\min }=10^{-4} \eta_{0}$. A weak hydrated crustal 
layer is initially included on top of the subducting plate (for detailed tests see Crameri and Tackley, 2015). The weak crustal layer is initially $d_{\text {crust }}=15$ $\mathrm{km}$ thick and differs from mantle material only in a lower yield strength with $\mu_{\text {crust }}=0.001$. Regular mantle material is converted into weak crust after it has resided at the surface for more than $10 \mathrm{Ma}$ and is converted to regular mantle again when subducted below a depth of $d>400 \mathrm{~km}$. The continental lithosphere that is included in some models consists of light and stronger (i.e., higher viscosity) material and has variable depth and width (see Table 1 for detailed parameters). Two different model setups are chosen to account for the rheological and buoyancy changes at $660 \mathrm{~km}$ depth. The first uses a simple viscosity jump by a factor 100 from the upper- to the lower mantle. The second, more elaborated model setup applies an actual phase change to additionally account for density variations using the parameters setup listed in Table 2

The model is internally heated with an internal heating rate of $5.44 \times$ $10^{-12} \mathrm{~W} / \mathrm{kg}$. The domain depth is intended to represent the whole mantle depth. The top boundary (including the air layer) is set to a constant 300 $\mathrm{K}$, while the bottom boundary is insulating by applying a zero heat flux condition. Top and bottom model-domain boundaries are free-slip, whereas the actual rocky surface is allowed to be a free surface thanks to an air layer as mentioned below. The side boundaries are periodic, and therefore do not interfere with the physical processes investigated in this study. Further physical and numerical parameter details are given in Table 1.

\subsection{Numerical Model}

A two-dimensional Cartesian geometry with an aspect ratio of $2: 1(x: z)$ is used for the key experiments of this study. This allows for efficient computation at high resolution using $512 \times 256$ grid points and 100 tracers per cell (see Table 3). Vertical grid refinement leads to a minimum vertical grid spacing of $3 \mathrm{~km}$ at shallow depth (see Figure 1a). The physical model described above is solved by the finite-difference/volume multigrid code STAGYY (e.g., Tackley, 2008). Three types of non-diffusive tracers are advected with the flow and track the composition, which is either mantle, weak crust, continent or air (see Figure 1b).

The model domain consists of the whole mantle depth plus (for free surface cases) a 'sticky-air' layer on top (Matsumoto and Tomoda, 1983; Schmeling et al. 2008). The sticky-air approach simulates a free surface in models

calculated on an Eulerian grid, if it is applied carefully (see Crameri et al. 
2012, for details and simple test conditions): The test condition $(C \ll 1)$ for the sticky-air layer in the current model is fulfilled for slab-driven topographic variations with $C_{\text {Stokes }}=0.013$. To track a freely evolving surface of the plate numerically, the code STAGYY tracks the composition (air or rock) on Lagrangian tracers that are advected with the flow. The actual vertical interface at every horizontal nodal point is then defined by a shape function averaging of all the uppermost rock and lowermost air tracer positions. Given the high number of tracers (i.e., on average 100 tracers per cell), we are then able to resolve a surface topography that is vertically much more accurate than the spacing between the nodal points of our Eulerian grid.

The dimensional scaling is the same as applied in Crameri and Tackley (2015). Crameri and Tackley (2015) further provides extensive numerical and physical testing for the models applied here.

\subsection{Initial Condition}

The model used here is set up with an initial subduction zone and thus assuming on-going subduction with a finitely long slab (see Figure 1c). Additionally, an initial divergent plate boundary is assumed at the end of the subducting plate's tail and the initial boundary layer thickness $w_{B L}$ increases away from this spreading center towards the subduction zone (on both subducting and overriding plate) according to the standard $\sqrt{a g e}$-law

$$
w_{B L}(x)=w_{B L, 0} \cdot \sqrt{\Delta x_{s c}}
$$

where $w_{B L, 0}$ is a constant controlling the maximum thickness of the plate, $x$ is the horizontal coordinate and $\Delta x_{s c}$ is the distance from the spreading center at any given position $x$. The radial component of the initial temperature is related to plate age as $T_{z}(x)=T_{0} \cdot \operatorname{erf}\left[(1-z) / w_{B L}(x)\right]$, with $T_{0}=0.64$ the initial, non-dimensional mantle temperature and $z$ the vertical coordinate ranging between 0 at the bottom to 1 at the top boundary. This leads to an initial divergent boundary (due to ridge push) that supports slab sinking at the beginning of the experiment. The plate's non-dimensional initial thickness at the trench is chosen to be $\sim 0.04 D$ based on the observation that this is a typical boundary layer thickness with the chosen $\mathrm{Ra}=10^{7}$ and $H=20$ (see Crameri and Tackley, 2015).

The initially 400-km long, straight slab (from trench to slab tip) has an initially constant thickness corresponding to the surface plate thickness at the trench. It is inclined to the surface plate by a certain angle, $\theta$ (see Table 3), 
which is defined as an initial condition at the shallow depth range of around $150-250 \mathrm{~km}$. In this study, the initial shallow-slab dip is varied between 20 and $60^{\circ}$. Given the initially straight nature of the model slab, shallower or steeper dips are not feasible due to unnatural coupling with the upper plate and an unnatural strong bending (i.e., kink) of the plate, respectively.

All experiments start with an initially flat surface and the free surface equilibrium is generally reached after $<1 \mathrm{Ma}$ (see Crameri et al., 2017).

\subsection{Diagnostics}

The efficient post-processing of all model data includes various fullyautomated diagnostics (see e.g,. Crameri et al., 2017) using the Geodynamic post-processing and visualisation toolbox STAGLAB (Crameri, 2017, freely available at www.fabiocrameri.ch/software). Diagnostic features that are discussed in the current study are mentioned hereafter.

\subsubsection{Upper-Plate Tilt}

The tilt angle of the upper plate is accurately and fully automatically derived and tracked through time within StagLab (see Supplementary Movie S1). The tilt of the plate's surface is measured as the vertical difference occurring on the upper-plate portion between the two horizontal locations that are 800 and $400 \mathrm{~km}$ away from the subduction trench (i.e., over a total distance of $400 \mathrm{~km}$ ) after removing the effect of local-scale topography undulations.

\subsubsection{Upper-Plate Inundation}

The (artificial) inundation of the upper plate is another accurately and fully-automatically derived diagnostics of STAGLAB (see Supplementary Movie $\mathrm{S} 1$ ). The inundation is here defined as the horizontal location of the upperplate surface that lies at sea level (neglecting the island arc and possible further land-inward depressions). Because there is no water in the model, the sea level is here defined as the mean topography over the whole model extent. Graphs showing the temporal evolution of inundation are normalised to the minimum value of inundation over the considered time period to highlight the variation of upper-plate inundation.

\subsubsection{Plate and Trench Velocities}

In the presence of plate boundaries, STAGLAB tracks upper- and lowerplate velocities. The individual plate velocities are measured in the cold 
core of the plates, close to the trench. It further derives the trench velocity by measuring the velocity of the upper plate just next to the trench. For comparison to the effective trench retreat, a theoretical trench velocity is calculated within STAGLAB for any given experimental state. Assuming a non-deformable slab, the theoretical trench velocity can be described by

$$
v_{T R, \text { theoretic }}=\frac{v_{\text {Stokes }}}{\tan \theta}
$$

where $v_{\text {Stokes }}$ is the vertical sinking velocity of the slab and $\theta$ is the shallow-slab dip angle (e.g., Capitanio et al., 2007).

\subsection{Visualisation}

The visualisation of the post-processed data is also done with STAGLAB. To prevent the most-common scientific visualisation pitfall, we do not use the rainbow colour map (see e.g., Borland and Ii, 2007). Instead, a new set of scientifically-proofed, perceptually-uniform colour maps is used, which is freely available on www.fabiocrameri.ch/visualisation.

\section{Results}

In order to investigate the time-dependent interaction between mantle flow and surface topography, we focus here on three key aspects, the dynamical control of (i) a simple upper-lower mantle viscosity jump, (ii) an upper-mantle phase transition, and (iii) a continental upper plate. These three key aspects are investigated with three corresponding model families named (i) Viscosity Jump, (ii) PhaseTransition and (iii) Continent, respectively (see Table 3). For all these models, we additionally vary the initial, shallow-slab dip angle (from $20^{\circ}$ up to $60^{\circ}$ ), as the slab dip angle has a major control on both subduction-related mantle flow and surface topography on Earth (e.g., Crameri et al., 2017).

\subsection{UM-LM Viscosity Jump}

The simplest model setup to investigate the dynamical impact of the UM-LM transition zone is also the control model of this study, meaning that additional complexities (e.g., phase transition and continental lithosphere) are added to it. This Viscosity Jump model features a simple, abrupt radial increase in mantle viscosity by a factor of 100 at 660-km depth (see Section 2 and Table 3); a setup that has also been used in previous studies (e.g., 
Garel et al., 2014). For this model setup, we perform various experiments with variable initial shallow-slab dips ranging from $20^{\circ}-60^{\circ}$ (Supplementary Figure S1).

The characteristic plate-velocity evolution for the Viscosity Jump model with an initial $30^{\circ}$ shallow-slab dip is shown in Supplementary Figure S2a. It is characterised by an initial slab free-fall phase $(\sim 0-5 \mathrm{Ma})$, where the slab-sinking velocity and the trench-retreat velocity are both high. The lowerplate velocity and the plate-convergence velocity are, as a direct result of the fast slab sinking, also high during this first, free-fall phase. After this initial, overall increase, plate velocities decrease dramatically once the slab starts to feel the presence of the higher-viscosity lower mantle and, even more so, when it finally collides with the boundary: This is termed the transitionzone interaction phase $(\sim 5-7 \mathrm{Ma})$. Finally, the plate velocities reach a somewhat steady-state phase $(>\sim 7 \mathrm{Ma})$, with constant, slow trench retreat and slab-sinking rates.

The sinking plates of all ViscosityJump-model experiments slow down after the transition-zone interaction, but easily penetrate the upper-lower mantle boundary (see e.g., Figure 2a-d and the Supplementary Movie S1). Due to the increased sinking-resistance of the higher-viscosity lower mantle, the slab generally starts, however, to develop a kink at (or close to) the transition zone. The actual kink polarity is thereby mainly controlled by the slab's sinking angle in the upper mantle. For initial low shallow-slab dip angles of $<30^{\circ}$, the slab tip bends upwards (Supplementary Figure S1c), while for steep angles of $>30^{\circ}$ it bends downwards (Supplementary Figure S1i and 1), or even backwards (Supplementary Figure S1o).

Not only does a higher-viscosity lower mantle deflect a sinking slab, it has also a crucial influence on the large-scale surface topography. It was previously shown that an UM-LM viscosity jump reduces the amplitudes of the individual surface-topography features of a convergent boundary (Crameri et al., 2017). Similar topographic changes through time can therefore be expected to occur additionally. And indeed, our models show that the slab's time-dependent transition-zone interaction causes dramatic topographic changes on the upper plate. The experiments indicate clearly that, once a sinking plate reaches the lower mantle, the upper plate tilts abruptly towards the subduction trench (Supplementary Figure S3). This sudden upper-plate tilt is clearly visible from the comparison of surface topography during the slab's free fall through the upper mantle and after the slab-transition-zone interaction (Figure 3a). Graphs comparing the slab-tip 
depth against the upper-plate tilt highlight the effect of the transition-zone interaction with surface topography even more clearly (see Figure 4a). As shown in Supplementary Figure S4a-e, the absolute upper-plate tilt (reaching $>0.07^{\circ}$ ) is largest for the shallowest-dipping slab considered here, while the abrupt change in tilt during transition-zone interaction (tilt gradient of up to $>0.06^{\circ}$ ) is largest for intermediately-dipping slabs (e.g., $30-40^{\circ}$ ). The extent over which the upper-plate tilt occurs is indicated in Figure 3 for an initial shallow-slab dip angle of $30^{\circ}$ and corresponds to around $1500 \mathrm{~km}$.

Another measure to quantify the temporal change of the topographic effect during slab-transition-zone interaction is given by upper-plate inundation. In these models, inundation is defined as the horizontal location of the upper-plate surface that lies at the sea level (as explained in Section 2.4.2. Temporal graphs highlight the variation of inundation during model evolution (see Figure 4b). In accordance to the upper-plate tilt evolution, inundation shows an abrupt increase during slab-transition-zone interaction. The dramatic land-inward shift of the sea level can reach up to $1000 \mathrm{~km}$ is more pronounced for low initial shallow-slab dips (Supplementary Figure S5a-e). This change in upper-plate tilt (and resulting inundation) happens over the short geologic time period of around $5 \mathrm{Ma}$ (Supplementary Figure S6a and b).

\subsection{UM-LM Phase Transition}

In order to capture the dynamics involved in the slab-transition-zone interaction more realistically, we add an actual phase transition on top of the viscosity jump to a second model setup named PhaseTransition (see Table 3). The upper-mantle transition zone has an important effect on the dynamic evolution of the subduction system as was already mentioned in Section 1. We test therefore the presence of the $660-\mathrm{km}$ phase transition on the model's dynamic evolution and, in particular again, its effect on the temporal plate surface deflection. Also for this model setup, we tested various initial shallow-slab dips in the range of $20^{\circ}-60^{\circ}$ (Supplementary Figure S7).

The Figure 2e-h and the Supplementary Movie S1 show the long-term time evolution of the subduction dynamics. We observe that an initial shallow-slab dip of $<50^{\circ}$ leads to intermediate slab stagnation at the uppermantle transition zone (Supplementary Figure S7). On the contrary, if the slab-tip portion reaches the 660-km depth level at a higher angle, it directly penetrates into the lower mantle. Depending on the slab sinking angle, a variable kink polarity in the slab tip develops again after colliding with the 
upper-mantle transition zone: In the case of initial shallow slab-angles (e.g., Supplementary Figure S7c and f), the slab experiences a kink where the oldest slab portion bends upwards (i.e., towards the upper plate), whereas in the case of a steep initial dip, the slab evolves a kink that bends the oldest slab portion downward (i.e., towards the subducting plate) as can be seen in Supplementary Figure S7l and o.

The characteristic plate-velocity evolution for a phase-transition model with an initial $30^{\circ}$ shallow-slab dip is shown in Supplementary Figure S2b. Overall, the plate velocities are similar to the ViscosityJump model with only a 660-km viscosity jump: Initial slab free-fall phase, UM-transition phase and quasi-steady state phase. There is, however, a clear difference during the quasi steady-state phase between 10 and $30 \mathrm{Ma}$ (compare Supplementary Figure S2a and b). The presence of a phase transition causes the slab to deform, which corresponds to a slab-tip flattening in the experiment with an initial $30^{\circ}$ slab dip (compare Supplementary Figure S7f and g). The still steeply-dipping slab portion behind the kink experiences temporally less sinking resistance as a result of the slab-tip flattening: Surface plate velocities can therefore remain higher until the slab-tip portion lies (nearly) flat on the $660-\mathrm{km}$ transition zone.

The particularly-interesting, abrupt tilting of the upper plate during slabtransition-zone interaction can again be clearly observed (Figures 3b and 5): As soon as the slab reaches the transition zone, it causes the upper plate, after a phase of relatively subtle tilt of around $0-0.02^{\circ}$ during UM subduction, to dip more strongly up to an actual plate tilt of around $0.08^{\circ}$ (Figure $4 \mathrm{c}$ ). The sudden change in upper-plate tilt is again strongest and more abrupt for intermediately-dipping slabs and reaching a tilt gradient of up to $0.06^{\circ}$ (Supplementary Figure S4f-j).

Temporal graphs of the variation of inundation during slab-transitionzone interaction show again an abrupt land-inward shift during slab-transitionzone interaction (see Figure $4 \mathrm{~d}$ ). The sudden variation can reach up to 800 $\mathrm{km}$ and is more pronounced for low initial shallow-slab dips (Supplementary Figure S5f-j). The time period over which the change in upper-plate tilt (and resulting inundation) happens is slightly longer than without an UM phase transition and takes around $10 \mathrm{Ma}$ (Supplementary Figure S6c and d).

\subsection{Continental Upper-Plate}

Our third model setup, named Continent (see Table 3), adds a continental upper-plate to the previous model, including both UM-LM viscosity jump 
and phase transition. It is intended to capture possible effects of a continent's deep roots on plate dynamics (see e.g., Conrad and Lithgow-Bertelloni, 2006), but also possible effects of a different plate rheology on the upper-plate's surface deformation (see e.g., Crameri et al., 2017). For this model setup, we varied therefore not only the initial shallow-slab dip $\left(20^{\circ}-60^{\circ}\right.$; Supplementary Figure S8), but also the width $(500-2500$ km; Supplementary Figure S9) and thickness $(100-250 \mathrm{~km}$; Supplementary Figure S10) of the floating continent for testing purposes. Our standard continent model has a 2000-km wide and $250-\mathrm{km}$ deep continent to account for the influence of a relatively inert upper plate and a strong plate-mantle coupling, respectively. From a numerical-modelling point of view, it is worth mentioning that this is the first time ever, a (simple) continent is successfully added to a global, dynamically self-consistent model of mantle convection, which also employs a free surface and realistic, single-sided subduction.

The temporal evolution of the continental upper-plate model compared to the two previous models setups without continental lithosphere is shown in Figure 2i-l and the Supplementary Movie S1. The general geometric evolution of the model (using an initial $30^{\circ}$ shallow-slab dip) appears similar to previous models without continental lithosphere: The slab sinks at a relatively high angle through the upper mantle, reaches the transition zone and gets deflected and bent to a lower-angle slab tip and a steeper slab tail. The comparison between experiments with variable initial slab dips (see Supplementary Figure S8) reveals, however, obvious differences in slab deformation styles: While the slab-tip bends forward (towards the mantle wedge) in the phase-transition model with an oceanic upper plate, it bends backwards (away from the mantle wedge) at high initial slab-dip angles when a continental upper-plate is present (see e.g., Supplementary Figure S8o). This is a direct result of the deep continent hampering trench retreat and hence causing a steeply-sinking slab. The deep continental roots extend throughout the low-viscosity asthenospheric layer and hence couple the continent to the lower part of the upper-mantle. The continental plate becomes thereby significantly less mobile and hampers trench retreat during the initial phases of model evolution (see Supplementary Figure S2c).

The crucial time-dependent topographic signal on the upper plate exerted by the slab-transition-zone interaction is, again, clearly visible. In fact, the large and stiff continental lithosphere is dramatically tilted abruptly over its full length (Figure 3c and Supplementary Figure S11). The amplitude and timing of the tilting is similar to the results obtained with an oceanic 
upper-plate (see Figure 4e): The tilt angle changes from a relatively subtle tilt of around $0-0.02^{\circ}$ during UM subduction to a more stronger tilt of up to around $0.07^{\circ}$. The sudden tilt increase is again most pronounced for low initial shallow-slab dips (Supplementary Figure S4k-o).

In accordance to the two previous model setups, there is a temporal landinward shift of inundation occurring during slab-transition-zone interaction (see Figure 4f). However, since in this case the buoyant continent is wide above sea level (see Supplementary Figure S11), the sudden variation in artificial inundation only reaches up to $300 \mathrm{~km}$ (Supplementary Figure S5ko). The time period over which the change in upper-plate tilt (and resulting inundation) happens is again slightly longer when a continental upper plate is present; it takes around $15 \mathrm{Ma}$ (Supplementary Figure S6e and f).

\section{Discussion}

\subsection{Slab Dynamics}

The upper-lower mantle transition zone, in particular the $660-\mathrm{km}$ discontinuity, is a crucial rheologic aspect in a mature subduction system. It dramatically affects the system's forcing and geometry. Free subduction (i.e., the undisturbed sinking of a cold plate) is strongly hindered by the upper-lower mantle transition zone. The models presented here reproduce previous findings (e.g., Kincaid and Olson, 1987; Zhong and Gurnis, 1995; Christensen, 1996; Zhong and Gurnis, 1997; Funiciello et al., 2003; Cížková and Bina. 2013; Garel et al., 2014; Agrusta et al., 2014, 2017) that the viscosity jump to the lower mantle decreases the slab-sinking rate (see Supplementary Figure S2a) and that the higher density of the lower mantle may cause the slab to (at least temporarily) vertically stagnate at the transition zone (see Figure 2e-h and Supplementary Movie S1). The angle at which the sinking slab tip approaches the transition zone is another key aspect to control its propensity to penetrate into the lower mantle (e.g., Kincaid and Olson, 1987). The variation of the initial, shallow-slab dip in our models also leads to a variation of the dip at which the slab finally arrives at $660 \mathrm{~km}$ depth. Major changes in slab dynamics are therefore observed in experiments with variable initial, shallow-slab dips: The slab either sinks at a low angle through the upper mantle and flattens at the transition zone (Supplementary Figure S7c), or it sinks at a steep angle, which allows the slab tip to dip into the lower mantle

(Supplementary Figure S7o). In the latter case especially, the slab is heavily deformed and deflected near the UM-LM transition zone. This finding that 
steep initial shallow-slab dip angles foster slab penetration of the transition zone is in accordance to the finding that young plates have the same effect (Agrusta et al., 2017); young plates are easier to bend and thus have a smaller natural bending radius (Capitanio et al., 2007; Wu et al., 2008; Goes et al., 2008; Capitanio et al., 2009).

Continents can additionally influence the propensity of a slab to enter the lower mantle directly as they can hamper trench movement and hence cause steeper slabs. In our models, thick continents are able to couple the surface-plate system to the higher-viscosity upper mantle as their deep roots exceed the thin low-viscosity asthenosphere just below the plate similarly to the previous study by Conrad and Lithgow-Bertelloni (2006). This fact has been observed already a while ago by a significant correlation between velocities and the fraction of continental area of the individual plates on Earth (Forsyth and Uyeda, 1975).

\subsection{Upper-Plate Tilt}

The most exciting finding of this study is probably the occurrence of an abrupt, large-scale tilting of the upper plate induced by the slab-transitionzone interaction. It is a solid and reoccurring topographic signal observed throughout all our model setups with a sub-vertical (in the direction of the subducting-plate movement) slab-transition-zone impact angle. This can be clearly seen from a compilation of upper-plate tilt and coinciding inundation variation during slab-transition-zone interaction for the different model setups in Figures 6 and 7. The clear, abrupt increase of upper-plate tilt of around $0.04^{\circ}$ and up to $>0.07^{\circ}$ occurs roughly over a distance of $>1000 \mathrm{~km}$ (see Figure 3) and over a time period of around $10 \mathrm{Ma}$. The sudden variation in tilt appears in the simplest model with only an UM-LM viscosity jump as well as in more elaborated models featuring an actual 660-km phase transition and even a continental upper-plate. The tilt gradient is smaller in the models with a continental upper plate as the increased buoyancy of the continent hampers tilting.

Yet, the signal clearly appears throughout all of our model setups. This indicates that the tilting is mainly due to the high viscosity of the lower mantle (relative to the upper mantle), rather than due to density contrast or upper-plate rheology. While the slab, or in other words the main driver of the system, is sinking through the upper mantle, the resulting flow in the surrounding mantle is spatially limited to the low-viscosity upper mantle. Once the slab reaches, however, the lower mantle, it starts to excite flow 
even in the higher-viscosity lower mantle. Due to the higher viscosity there, the resulting flow-cell below the upper plate becomes significantly larger (see Figure 5c and $\mathrm{f}$, and the schematic illustration of Figure 8). This subductioninduced large-scale mantle-flow cell has already previously been attributed to cause compression and mountain building in the upper plate close to the trench (Faccenna et al., 2013, 2017; Crameri et al., 2017). The transition from the localised upper-mantle flow in the wedge close to the trench to the larger, whole-mantle flow additionally produces a significantly wider (i.e., more land-inward) area of downwelling at the bottom of the upper plate. We show here that this then finally results in a more land-inward suction at the base of the plate and a sudden and significant increase of upper-plate tilt; a tilt that might coincide with a dramatic increase in continental inundation.

The upper-plate tilt increase during slab-transition-zone interaction is largest for initial shallow-slab dip angles of $\sim 30^{\circ}$ throughout all our model setups (see Figure 6). The general decrease towards steeper slabs can be explained by a geometric effect: Steeper slabs cannot excite a wide flow cell below the upper plate that is necessary to pull down the upper plate significantly. This upper-plate tilt has important consequences. The most apparent one is the directly correlated increase in continental inundation, when the tilted surface lies approximately at sea level (see e.g., Figure 5a and $\mathrm{d}$ ). We found abrupt inundation variations on the order of up to 1000 km (Figure 7).

On Earth, there are many examples of time-dependent continent-wide tilting captured in the geologic record. Of the many theories published outlining possible mechanisms to cause an upper plate to tilt abruptly, none attributes the tilting directly to the slab-transition-zone collision. The continental tilting of the Russian platform during the Devonian to Permian (Mitrovica et al., 1996) and the subsidence of the Karoo Basin during the Late Carboniferous to Early Triassic (Pysklywec and Mitrovica, 1999) were, for example, both attributed to the general occurrence of subduction. Another, more specific example happened to the North America plate. There the maximum tilt of the continental plate was, for example, reconstructed to have intermediately reached $\sim 0.02^{\circ}$ (a tilt amplitude of $3 \mathrm{~km}$ over a horizontal distance of $1400 \mathrm{~km}$ ) during the Phanerozoic (Mitrovica et al., 1989). This tilting has been attributed to a flat-slab phase. A similar continental tilting attributed to general subduction was found for Australia, which experienced a tilt of $\sim 0.08^{\circ}$ during the Eocene (DiCaprio et al., 2009; Heine et al., 2010). The significant slab accumulation immediately beneath or at the transition 
zone in this area (Hall and Spakman, 2002) provides an obvious candidate for the source of the plate downward pull. Additionally, all the previouslymentioned numbers fall in the range of the observed upper-plate tilts of our models and might indicate ongoing slab-transition-zone interaction in these regions during these time periods. Whether this is indeed the case for each of these examples has, of course, to be studied more carefully. Either way, the slab-transition-zone collision outlined in the present study is certainly a viable mechanism to explain long-wavelength continental tilting.

\subsection{Model Limitations}

By definition, models are not - and should not be - perfect representations of nature. It is, however, important to understand their limitations, especially when comparisons between model and nature are drawn. We discuss here the key limitations to our modelling approach even though this study aims mainly at better understanding the basic fluid dynamics behind the subduction system.

The 2-D models presented here are calculated in relatively narrow model domains with an aspect ratio of $2: 1$, which enables efficient calculation. Possible numerical artefacts arising from the relatively small model domain are prevented by using periodic side-boundaries and ruled out by test with wider model domains (see Supplementary Figure S12). Another test validates our results obtained by models run in a simpler Cartesian instead of a more nature-like cylindrical geometry: The abrupt upper-plate tilt during slabtransition-zone interaction is apparent also for a model in a more realistic cylindrical geometry (see Supplementary Figures S13 and S14).

Our simple models additionally neglect the presence of nature-like 3-D flow in the mantle and at the surface. As such, they cannot account for toroidal mantle flow as is, for example, expected to occur at the edges of slabs (Funiciello et al. 2004), or for the characteristic spiral flow behind the slab (see e.g., Crameri and Tackley, 2014). However, another (computationallyexpensive) test case in a 3-D geometry featuring a 1000-km wide slab gap to enable toroidal mantle return flow still yielded a consistent, similarly-abrupt upper-plate tilt during slab-transition-zone interaction (see Supplementary Figure S15). Yet, it remains important to test this more carefully with additional 3-D models in the future. This also because our models do not account for the lateral variation of slab dip, and hence the slab's propensity of penetrating into the lower mantle, along a subduction zone's strike direction. Therefore, they neglect the fact that subduction zones might have a portion of 
the slab lying on the transition zone, while the other portion is simultaneously sinking into deeper parts of the Earth. However, we expect little contribution from an additional, trench-parallel horizontal flow component to our key finding: The upper-plate tilt is mostly controlled by poloidal (i.e., vertical) subduction-induced flow in the mantle wedge. A weakening in the slab-plate coupling through, for example, a low-viscosity horizontal layer near the base of the plate might, however, reduce the vertical amplitude of the resulting deflection. Possible decoupling agents might be wide-spread weakening by melting and/or volatiles like $\mathrm{CO}_{2}$ or $\mathrm{H}_{2} \mathrm{O}$, something worth testing in the future. Along the same line, it has previously been shown that a low-viscosity mantle wedge reduces the downward pull on the upper plate resulting in a shallower back-arc depression (Billen and Gurnis, 2001, 2003, Crameri et al., 2017). Our additional tests with the addition of such a low-viscosity mantle wedge (see Supplementary Figure S16) show that this decoupling-effect is effective only for regions close $(<500 \mathrm{~km})$ to the subduction trench. A lowviscosity mantle wedge does therefore not hamper the abrupt, large-scale tilting of the upper plate in any of our three main model setups.

Time- and space-dependent changes in slab buoyancy are not fully accounted for in our models but could affect the inundation: The subduction of a thick buoyant crust could lead to uplift on the upper plate, reducing the extent of inundation (Dávila and Lithgow-Bertelloni, 2015; Eakin et al., 2014).

The models presented here use a parameterised, visco-plastic definition of rheology, neglecting possible effects of elasticity like lithospheric flexure. Even though previous studies have shown that the difference between viscoplastic and visco-elasto-plastic models is minor in terms of Earth-like subduction dynamics (e.g., Schmeling et al., 2008), possible effects of elastic stresses on long-wavelength surface topography should certainly be investigated carefully in future studies.

The continents added to some of the models presented here are weaker and heavier than generally applied 'floating continents' of similar models (compare e.g., Rolf and Tackley, 2011). This is possible due to the relatively short time period considered here $(<100 \mathrm{Ma})$. Really strong and buoyant continents seem, however, to be necessary to remain intact and at the surface over longer time periods. More realistic mechanical properties should in general be tested carefully in future studies for models similar to the ones presented here (e.g., Burov, 2011). 


\section{Conclusions}

We present a novel, visco-plastic model for the temporal evolution of mantle convection with dynamically self-consistent, single-sided subduction. The model features temporally-stable single-sided subduction, stronger plates with yield parameters close to laboratory values, accurate subduction-zone topography, and numerically-stable floating continents at a free rock-air interface. This state-of-the-art model is used for basic-fluid dynamic modelling that provides new insights into the long-term evolution of subduction and subduction-induced topography.

We focus here on the dynamic interaction of the slab with the upper-lower mantle transition zone. Our systematic, fluid-dynamic modelling approach involves three main model setups with increasing complexity. The first includes a simple upper-mantle viscosity jump, the second adds a $660-\mathrm{km}$ phase transition to it, and the third even adds a continental upper plate. The phasetransition experiments indicate that steeper initial shallow-slab dips increase the propensity for the slab to penetrate directly into the lower mantle. Along the same line, our other experiments show that a thick continental upper plate hampers trench retreat via increased coupling with the lower mantle. The hampered trench retreat then steepens the slab, which further increases the slab's propensity to penetrate the transition zone directly.

Most interestingly however, all our models reveal, for the first time, a clear and time-dependent topographic footprint of the slab-transition-zone interaction that is associated with the viscosity jump between upper- and lower mantle: The upper plate suddenly tilts towards the subduction zone by around $0.05^{\circ}$ and over around $10 \mathrm{Ma}$. This characteristic upper-plate tilt evolution and the $900-\mathrm{km}$ increase of inundation extent that goes along with it, are visible even in our simple Viscosity Jump model setup, which only employs a viscosity jump at $660-\mathrm{km}$ depth. The sudden upper-plate tilt upon slab-transition-zone interaction occurs also in more complex models with an actual phase transition and even a continental upper plate. This new discovery appears to be a robust feature even for various different model-mantle geometries (e.g., in a cylindrical setup and even 3-D) as long as the slab-tip impact angle is subvertically (i.e., dipping in the direction of the subducting plate movement). As soon as such a sub-vertical slab interacts with the lower mantle, it excites a much larger subduction-induced flow cell underneath the upper plate due to the displacement of higher-viscosity material in the lower mantle. The discovery of this unknown and yet highly-important 
interaction between the deep planetary mantle and its surface might proof as a valid explanation for the many occurrences of abrupt, continent-wide tilting described in the geologic record on Earth.

\section{Acknowledgment}

This work was partly supported by the Research Council of Norway through its Centres of Excellence funding scheme, project number 223272. The models presented here were computed using a UNINETT Sigma2 computational resource allocation (Notur NN9283K and NorStore NS9029K). The authors thank Paul Tackley for providing the code STAGYY. The postprocessing software STAGLAB, the perceptually-uniform colour maps, as well as further methodical details and the raw numerical data can be requested from the author (www.fabiocrameri.ch).

Finally, we are thankful to have known Evgenii Burov and are truly grateful for his immense contribution to the Geodynamics community, in particular through his generous support of young scientists.

Agrusta, R., J. van Hunen, and S. Goes (2014), The effect of metastable pyroxene on the slab dynamics, Geophys. Res. Lett., 41(24), 8800-8808.

Agrusta, R., S. Goes, and J. van Hunen (2017), Subducting-slab transitionzone interaction: Stagnation, penetration and mode switches, Earth and Planetary Science Letters, 464, 10-23, doi:10.1016/0040-1951(85)90209-4.

Bijwaard, H., W. Spakman, and E. R. Engdahl (1998), Closing the gap between regional and global travel time tomography, J. Geophys. Res., 103 (B12), 30,055-30,078.

Billen, M. I., and M. Gurnis (2001), A low viscosity wedge in subduction zones, Earth and Planetary Science Letters, 193(1-2), 227-236.

Billen, M. I., and M. Gurnis (2003), Comparison of dynamic flow models for the Central Aleutian and Tonga-Kermadec subduction zones, Geochem. Geophys. Geosyst., 4(4), 1035, doi:10.1029/2001GC000295.

Bina, C. R. (1991), Mantle discontinuities, Reviews of Geophysics Supplement, 29, 783-793.

Borland, D., and R. M. T. Ii (2007), Rainbow color map (still) considered harmful, IEEE Computer Graphics and Applications, 27(2), 14-17. 
Burov, E. B. (2011), Rheology and strength of the lithosphere, Marine and Petroleum Geology, 28(8), 1402-1443.

Běhounková, M., and H. Čížková (2008), Long-wavelength character of subducted slabs in the lower mantle, Earth and Planetary Science Letters, 275(1-2), 43-53.

Capitanio, F., G. Morra, and S. Goes (2007), Dynamic models of downgoing plate-buoyancy driven subduction: Subduction motions and energy dissipation, Earth and Planetary Science Letters, 262(1-2), 284-297.

Capitanio, F. A., G. Morra, and S. Goes (2009), Dynamics of plate bending at the trench and slab-plate coupling, Geochem. Geophys. Geosyst., 10(4), Q04,002.

Christensen, U. R. (1996), The influence of trench migration on slab penetration into the lower mantle, Earth and Planetary Science Letters, 140(1-4), $27-39$.

Conrad, C. P., and C. Lithgow-Bertelloni (2006), Influence of continental roots and asthenosphere on plate-mantle coupling, Geophys. Res. Lett., 33(5), L05,312.

Crameri, F. (2017), StagLab: Post-Processing and Visualisation in Geodynamics, in EGU General Assembly Abstracts, vol. 19, pp. EGU2017-8528.

Crameri, F., and P. Tackley (2014), Spontaneous development of arcuate single-sided subduction in global 3-D mantle convection models with a free surface, J. Geophys. Res. Solid Earth, 119(7), 5921-5942, doi:10.1002/ 2014JB010939.

Crameri, F., and P. Tackley (2015), Parameters controlling dynamically selfconsistent plate tectonics and single-sided subduction in global models of mantle convection, J. Geophys. Res. Solid Earth, 120(5), 3680-3706.

Crameri, F., H. Schmeling, G. J. Golabek, T. Duretz, R. Orendt, S. J. H. Buiter, D. A. May, B. J. P. Kaus, T. V. Gerya, and P. J. Tackley (2012), A comparison of numerical surface topography calculations in geodynamic modelling: An evaluation of the 'sticky air' method, Geophysical Journal International, 189(1), 38-54, doi:10.1111/j.1365-246X.2012.05388.x. 
Crameri, F., C. R. Lithgow-Bertelloni, and P. J. Tackley (2017), The dynamical control of subduction parameters on surface topography, Geochem. Geophys. Geosyst., 18(4), 1661-1687, doi:10.1002/2017GC006821.

Dávila, F. M., and C. Lithgow-Bertelloni (2015), Dynamic uplift during slab flattening, Earth and Planetary Science Letters, 425, 34 - 43, doi:10.1016/ j.epsl.2015.05.026.

Dávila, F. M., C. Lithgow-Bertelloni, and M. Giménez (2010), Tectonic and dynamic controls on the topography and subsidence of the Argentine Pampas: The role of the flat slab, Earth and Planetary Science Letters, 295(12), 187-194.

DiCaprio, L., M. Gurnis, and D. Müller (2009), Long-wavelength tilting of the Australian continent since the Late Cretaceous, Earth and Planetary Science Letters, 278(3-4), 175-185.

Duretz, T., T. V. Gerya, and D. A. May (2011), Numerical modelling of spontaneous slab breakoff and subsequent topographic response, Tectonophysics, 502(1-2), 244-256.

Eakin, C. M., C. Lithgow-Bertelloni, and F. M. Dávila (2014), Influence of Peruvian flat-subduction dynamics on the evolution of western Amazonia, Earth and Planetary Science Letters, 404(0), 250-260.

Faccenna, C., T. W. Becker, C. P. Conrad, and L. Husson (2013), Mountain building and mantle dynamics, Tectonics, 32(1), 80-93.

Faccenna, C., O. Oncken, A. F. Holt, and T. W. Becker (2017), Initiation of the Andean orogeny by lower mantle subduction, Earth and Planetary Science Letters, 463, 189-201.

Forsyth, D., and S. Uyeda (1975), On the relative importance of the driving forces of plate motion*, Geophysical Journal of the Royal Astronomical Society, 43(1), 163-200.

Forte, A. M., and J. X. Mitrovica (1996), New inferences of mantle viscosity from joint inversion of long-wavelength mantle convection and post-glacial rebound data, Geophys. Res. Lett., 23(10), 1147-1150. 
Fukao, Y., and M. Obayashi (2013), Subducted slabs stagnant above, penetrating through, and trapped below the $660 \mathrm{~km}$ discontinuity, J. Geophys. Res. Solid Earth, 118(11), 5920-5938.

Funiciello, F., C. Faccenna, D. Giardini, and K. Regenauer-Lieb (2003), Dynamics of retreating slabs: 2. Insights from three-dimensional laboratory experiments, J. Geophys. Res., 108(B4), 2207, doi:doi:10.1029/ 2001JB000896.

Funiciello, F., C. Faccenna, and D. Giardini (2004), Role of lateral mantle flow in the evolution of subduction systems: insights from laboratory experiments, Geophysical Journal International, 157(3), 1393-1406.

Garel, F., S. Goes, D. R. Davies, J. H. Davies, S. C. Kramer, and C. R. Wilson (2014), Interaction of subducted slabs with the mantle transition-zone: A regime diagram from $2-\mathrm{D}$ thermo-mechanical models with a mobile trench and an overriding plate, Geochem. Geophys. Geosyst., 15(5), 1739-1765, doi:10.1002/2014GC005257.

Gérault, M., L. Husson, M. S. Miller, and E. D. Humphreys (2015), Flat-slab subduction, topography, and mantle dynamics in southwestern Mexico, Tectonics, 34(9), 1892-1909, doi:10.1002/2015TC003908.

Goes, S., F. A. Capitanio, and G. Morra (2008), Evidence of lower-mantle slab penetration phases in plate motions, Nature, 451, 981-984.

Goes, S., R. Agrusta, J. van Hunen, and F. Garel (2017), Subductiontransition zone interaction: A review, Geosphere, 13(3), 644-664, doi: 10.1130/ges01476.1.

Grand, S. P. (2002), Mantle shear-wave tomography and the fate of subducted slabs, Philosophical Transactions of the Royal Society of London. Series A:Mathematical, Physical and Engineering Sciences, 360(1800), 2475-2491.

Griffiths, R. W., R. I. Hackney, and R. D. van der Hilst (1995), A laboratory investigation of effects of trench migration on the descent of subducted slabs, Earth and Planetary Science Letters, 133(1), 1-17.

Gurnis, M. (1988), Large-scale mantle convection and the aggregation and dispersal of supercontinents, Nature, 332(6166), 695-699. 
Gurnis, M. (1992), Rapid continental subsidence following the initiation and evolution of subduction, Science, 255(5051), 1556-1558.

Hager, B. H. (1984), Subducted slabs and the geoid: Constraints on mantle rheology and flow, J. Geophys. Res., 89(B7), 6003-6015.

Hager, B. H., and M. A. Richards (1989), Long-wavelength variations in earth's geoid: Physical models and dynamical implications, Philos Trans $R$ Soc Lond A, 328(1599), 309.

Hall, R., and W. Spakman (2002), Subducted slabs beneath the eastern Indonesia-Tonga region: insights from tomography, Earth and Planetary Science Letters, 201 (2), 321-336.

Heine, C., R. D. Müller, B. Steinberger, and L. DiCaprio (2010), Integrating deep Earth dynamics in paleogeographic reconstructions of Australia, Tectonophysics, 483(1-2), 135-150.

Jarrard, R. D. (1986), Relations among subduction parameters, Rev. Geophys., $24(2), 217-284$.

Kincaid, C., and P. Olson (1987), An experimental study of subduction and slab migration, J. Geophys. Res., 92(B13), 13,832-13,840.

King, S. D., and G. Masters (1992), An inversion for radial viscosity structure using seismic tomography, Geophys. Res. Lett., 19(15), 1551-1554.

Lallemand, S., A. Heuret, and D. Boutelier (2005), On the relationships between slab dip, back-arc stress, upper plate absolute motion, and crustal nature in subduction zones, Geochem. Geophys. Geosyst., 6(9), Q09,006, doi:10.1029/2005GC000917.

Lee, C., and S. D. King (2011), Dynamic buckling of subducting slabs reconciles geological and geophysical observations, Earth and Planetary Science Letters, 312(3-4), 360-370.

Li, X.-D., and B. Romanowicz (1996), Global mantle shear velocity model developed using nonlinear asymptotic coupling theory, J. Geophys. Res., 101 (B10), 22,245-22,272.

Li, Z.-H., and N. M. Ribe (2012), Dynamics of free subduction from 3-D boundary element modeling, J. Geophys. Res., $117(\mathrm{~B} 6), \mathrm{B} 06,408$. 
Lithgow-Bertelloni, C., and M. Gurnis (1997), Cenozoic subsidence and uplift of continents from time-varying dynamic topography, Geology, 25(8), 735738.

Matsumoto, T., and Y. Tomoda (1983), Numerical simulation of the initiation of subduction at the fracture zone, Journal of Physics of the Earth, $31(3), 183-194$.

Mitrovica, J. X., C. Beaumont, and G. T. Jarvis (1989), Tilting of continental interiors by the dynamical effects of subduction, Tectonics, 8(5), 10791094.

Mitrovica, J. X., R. N. Pysklywec, C. Beaumont, and A. Rutty (1996), The devonian to permian sedimentation of the Russian Platform: An example of subduction-controlled long-wavelength tilting of continents, Journal of Geodynamics, 22(1), 79-96.

Moresi, L., and V. Solomatov (1998), Mantle convection with a brittle lithosphere: thoughts on the global tectonic styles of the Earth and Venus, Geophysical Journal International, 133(3), 669-682.

Pysklywec, R. N., and J. X. Mitrovica (1999), The role of subduction-induced subsidence in the evolution of the Karoo Basin, The Journal of Geology, $107(2), 155-164$, doi:10.1086/314338.

Ribe, N. M. (2010), Bending mechanics and mode selection in free subduction: a thin-sheet analysis, Geophysical Journal International, 180(2), $559-576$.

Ribe, N. M., E. Stutzmann, Y. Ren, and R. van der Hilst (2007), Buckling instabilities of subducted lithosphere beneath the transition zone, Earth and Planetary Science Letters, 254(1-2), 173-179.

Ricard, Y., M. Richards, C. Lithgow-Bertelloni, and Y. Le Stunff (1993), A geodynamic model of mantle density heterogeneity, J. Geophys. Res., 98(B12), 21,895-21,909.

Rolf, T., and P. J. Tackley (2011), Focussing of stress by continents in 3D spherical mantle convection with self-consistent plate tectonics, Geophys. Res. Lett., 38(18), L18,301, doi:10.1029/2011GL048677. 
Russell, M., and M. Gurnis (1994), The planform of epeirogeny: vertical motions of Australia during the Cretaceous, Basin Research, 6(2-3), 6376.

Sandiford, M. (2007), The tilting continent: A new constraint on the dynamic topographic field from Australia, Earth and Planetary Science Letters, 261 (1-2), 152-163.

Schmeling, H., A. Babeyko, A. Enns, C. Faccenna, F. Funiciello, T. Gerya, G. Golabek, S. Grigull, B. Kaus, G. Morra, S. Schmalholz, and J. van Hunen (2008), A benchmark comparison of spontaneous subduction models-Towards a free surface, Physics of the Earth and Planetary Interiors, 171(1-4), 198-223, doi:10.1016/j.pepi.2008.06.028.

Stegman, D., R. Farrington, F. Capitanio, and W. Schellart (2010), A regime diagram for subduction styles from 3-D numerical models of free subduction, Tectonophysics, 483(1-2), 29-45.

Tackley, P. J. (2000), Self-consistent generation of tectonic plates in timedependent, three-dimensional mantle convection simulations - Part 1: Pseudo-plastic yielding, Geochem. Geophys. Geosyst., 1(8), 1-45.

Tackley, P. J. (2008), Modelling compressible mantle convection with large viscosity contrasts in a three-dimensional spherical shell using the yinyang grid, Physics of the Earth and Planetary Interiors, 171 (1-4), 7-18, doi:10.1016/j.pepi.2008.08.005.

Taramón, J. M., J. Rodríguez-González, A. M. Negredo, and M. I. Billen (2015), Influence of cratonic lithosphere on the formation and evolution of flat slabs: Insights from 3-D time-dependent modeling, Geochem. Geophys. Geosyst., 16(9), 2933-2948, doi:10.1002/2015GC005940.

Trompert, R., and U. Hansen (1998), Mantle convection simulations with rheologies that generate plate-like behaviour, Nature, 395, 686-689.

van der Hilst, R., E. Engdahl, W. Spakman, and G. Nolet (1991), Tomographic imaging of subducted lithosphere below northwest Pacific island arcs, Nature, 353, 37-42. 
Č́žková, H., and C. R. Bina (2013), Effects of mantle and subductioninterface rheologies on slab stagnation and trench rollback, Earth and Planetary Science Letters, 379, 95-103.

Wu, B., C. P. Conrad, A. Heuret, C. Lithgow-Bertelloni, and S. Lallemand (2008), Reconciling strong slab pull and weak plate bending: The plate motion constraint on the strength of mantle slabs, Earth and Planetary Science Letters, 272(1-2), 412-421.

Zhong, S., and M. Gurnis (1994), Controls on trench topography from dynamic models of subducted slabs, J. Geophys. Res., 99(B8), 15,683-15,695.

Zhong, S., and M. Gurnis (1995), Mantle convection with plates and mobile, faulted plate margins, Science, 267(5199), 838-843.

Zhong, S., and M. Gurnis (1997), Dynamic interaction between tectonic plates, subducting slabs, and the mantle, Earth Interact., 1(3), 1-18, doi: 10.1175/1087-3562(1997)001<0001:DIBTPS $\rangle$ 2.3.CO;2.

Zhong, S., M. T. Zuber, L. Moresi, and M. Gurnis (2000), Role of temperature-dependent viscosity and surface plates in spherical shell models of mantle convection, J. Geophys. Res., 105(B5), 11,063-11,082. 
Table 1: Control Model Parameters

\begin{tabular}{|c|c|c|c|c|}
\hline Parameter & Symbol & $\begin{array}{l}\text { Non-dimensional } \\
\text { value }\end{array}$ & $\begin{array}{l}\text { Dimensional } \\
\text { value }\end{array}$ & Unit \\
\hline Reference viscosity & $\eta_{0}$ & 1 & $10^{22}$ & $\mathrm{Pas}$ \\
\hline Mantle depth & $D$ & 1 & 2890 & $\mathrm{~km}$ \\
\hline Upper-mantle depth & $D_{U M}$ & 0.23 & 660 & $\mathrm{~km}$ \\
\hline Gravitational acceleration & $g$ & - & 9.81 & $\mathrm{~m} \mathrm{~s}^{-2}$ \\
\hline Thermal conductivity & $k$ & - & 3 & $\mathrm{~W} \mathrm{~m}^{-1} \mathrm{~K}^{-1}$ \\
\hline Thermal diffusivity & $\kappa$ & 1 & $10^{-6}$ & $\mathrm{~m}^{2} \mathrm{~s}^{-1}$ \\
\hline Thermal expansivity & $\alpha$ & - & $3 \times 10^{-5}$ & $\mathrm{~K}^{-1}$ \\
\hline Temperature gradient & $\Delta T$ & 1 & 2500 & $\mathrm{~K}$ \\
\hline Reference density & $\rho_{0}$ & 1 & 3300 & $\mathrm{~kg} \mathrm{~m}^{-3}$ \\
\hline Heat capacity & $C p_{0}$ & - & 1200 & $\mathrm{~J} \mathrm{~kg}^{-1} \mathrm{~K}^{-1}$ \\
\hline Internal heating rate & $H$ & 20 & $4.92 \times 10^{-12}$ & $\mathrm{~W} \mathrm{~kg}^{-1}$ \\
\hline \multicolumn{5}{|l|}{ Plasticity } \\
\hline Friction coefficient & $\mu$ & 0.25 & & \\
\hline Cohesion & $C$ & 1577 & $10 \times 10^{6}$ & $\mathrm{~Pa}$ \\
\hline Max. yield stress & $\sigma_{y, \text { const }}$ & $9.5 \times 10^{4}$ & $600 \times 10^{6}$ & $\mathrm{~Pa}$ \\
\hline \multicolumn{5}{|l|}{ Diffusion Creep } \\
\hline Activation energy & $E_{a c t}$ & 14.43 & 300 & $\mathrm{~kJ} \mathrm{~mol}^{-1}$ \\
\hline Activation volume & $V_{a c t}$ & 9.47 & $2 \times 10^{-6}$ & $\mathrm{~m}^{3} \mathrm{~mol}$ \\
\hline \multicolumn{5}{|l|}{ Dislocation Creep } \\
\hline Activation energy & $E_{a c t, N L}$ & 20.7 & 430 & $\mathrm{~kJ} \mathrm{~mol}^{-1}$ \\
\hline Activation volume & $V_{a c t, N L}$ & 4.74 & $1 \times 10^{-6}$ & $\mathrm{~m}^{3} \mathrm{~mol}$ \\
\hline Powerlaw index & $n$ & 3.5 & & \\
\hline \multicolumn{5}{|l|}{ Sticky-Air Layer } \\
\hline Thickness & $d_{s t}$ & 0.05 & 145 & $\mathrm{~km}$ \\
\hline Viscosity & $\eta_{s t}$ & $10^{-3} \eta_{0}$ & $10^{20}$ & Pas \\
\hline C-condition ${ }^{a}$ & $C_{\text {Stokes }}$ & 0.013 & & \\
\hline \multicolumn{5}{|l|}{ Weak Crustal Layer } \\
\hline Thickness & $d_{\text {crust }}$ & 0.005 & 15.2 & $\mathrm{~km}$ \\
\hline Viscosity & $\eta_{\text {crust }}$ & $\eta_{0}$ & $10^{22}$ & Pas \\
\hline Friction coefficient & $\mu_{\text {crust }}$ & 0.001 & & \\
\hline Cohesion & $C_{\text {crust }}$ & 1577 & $10 \times 10^{6}$ & $\mathrm{~Pa}$ \\
\hline \multicolumn{5}{|l|}{ Continent ${ }^{b}$} \\
\hline Thickness & $d_{C}$ & 0.089 & 250.0 & $\mathrm{~km}$ \\
\hline Width & $w_{C}$ & 0.692 & 2000.0 & $\mathrm{~km}$ \\
\hline Viscosity & $\eta_{C}$ & $10 \eta_{0}$ & $10^{23}$ & Pas \\
\hline Friction coefficient & $\mu_{C}$ & 0.5 & & \\
\hline Buoyancy difference & $B_{C}$ & 0.087 & -25.0 & $\mathrm{~kg} \mathrm{~m}^{-3}$ \\
\hline
\end{tabular}

${ }^{a}$ Indicates suitable free-surface approximation with sticky-air approach if $C_{\text {Stokes }} \ll 1$ (Crameri et al. 2012). ${ }^{b}$ If applied. 
Table 2: Phase-Transition Model Parameters

\begin{tabular}{llccl}
\hline & & Non-dimensional & Dimensional & \\
Parameter & Symbol & value & value & Unit \\
\hline Transition-zone depth & $D_{U M}$ & 0.23 & 660 & $\mathrm{~km}$ \\
Viscosity-jump factor & $\Delta \eta_{600}$ & 30 & - & - \\
Density contrast & $\Delta \rho_{600}$ & 0.1 & 341 & $\mathrm{~kg} \mathrm{~m}^{-3}$ \\
Clapeyron slope & $\gamma_{600}$ & -0.064 & $-2.5 \times 10^{-6}$ & $\mathrm{~Pa} \mathrm{~K}^{-1}$ \\
Diffusion Creep (UM) & & & & \\
Activation energy & $E_{a c t}$ & 14.43 & 300 & $\mathrm{~kJ} \mathrm{~mol}^{-1}$ \\
Activation volume & $V_{a c t}$ & 18.94 & $4 \times 10^{-6}$ & $\mathrm{~m}^{3} \mathrm{~mol}$ \\
Diffusion Creep (LM) & & & & \\
Activation energy & $E_{a c t}$ & 9.62 & 200 & $\mathrm{~kJ} \mathrm{~mol}^{-1}$ \\
Activation volume & $V_{a c t}$ & 5.21 & $1.1 \times 10^{-6}$ & $\mathrm{~m}^{3} \mathrm{~mol}$ \\
Dislocation Creep (UM) & & & & \\
Activation energy & $E_{a c t, N L}$ & 20.7 & 430 & $\mathrm{~kJ} \mathrm{~mol}^{-1}$ \\
Activation volume & $V_{a c t, N L}$ & 4.74 & $1 \times 10^{-6}$ & $\mathrm{~m}^{3} \mathrm{~mol}$ \\
Powerlaw index & $n$ & 3.5 & - & - \\
Dislocation Creep $(L M)$ & & & & \\
Activation energy & $E_{a c t, N L}$ & 20.7 & 430 & $\mathrm{~kJ} \mathrm{~mol}^{-1}$ \\
Activation volume & $V_{a c t, N L}$ & 4.74 & $1 \times 10^{-6}$ & $\mathrm{~m}^{3} \mathrm{~mol}$ \\
Powerlaw index & $n$ & 3.5 & - & - \\
\hline
\end{tabular}

Table 3: Model Setups Presented In This Study

\begin{tabular}{|c|c|c|c|c|c|c|}
\hline Tag & $\begin{array}{c}\text { Resolution } \\
(n x \times n y \times n z)\end{array}$ & $\begin{array}{c}\text { Initial } \\
\text { Slab Dip }\end{array}$ & $\begin{array}{c}\text { UM-LM } \\
\text { Viscosity Jump } \\
\Delta \eta_{M T}\end{array}$ & $\begin{array}{c}\text { 660-km } \\
\text { Phase } \\
\text { Transition }\end{array}$ & $\begin{array}{l}\text { Continental } \\
\text { Upper Plate }\end{array}$ & $\begin{array}{c}\text { Varied } \\
\text { Physical } \\
\text { Complexity }\end{array}$ \\
\hline ViscosityJump & $512 \times 1 \times 256$ & $30^{\circ}$ & 100 & no & no & - \\
\hline Suite1 & $512 \times 1 \times 256$ & $20-60^{\circ}$ & 100 & no & no & initial slab dip \\
\hline Suite2 & $512 \times 1 \times 256$ & $30^{\circ}$ & $30-100$ & no & no & viscosity jump factor \\
\hline Test1 & $512 \times 1 \times 256$ & $30^{\circ}$ & 100 & no & no & low visc. mantle wedge ${ }^{a}$ \\
\hline PhaseTransition & $512 \times 1 \times 256$ & $30^{\circ}$ & 30 & yes & no & - \\
\hline Suite3 & $512 \times 1 \times 256$ & $20-60^{\circ}$ & 30 & yes & no & initial slab dip \\
\hline Test2 & $2048 \times 1 \times 256$ & $30^{\circ}$ & 30 & yes & no & $8: 1$ aspect ratio domain \\
\hline Test3 & $512 \times 1 \times 256$ & $\sim 30^{\circ}$ & 30 & yes & no & cylindrical domain \\
\hline Test4 & $512 \times 256 \times 256$ & $25^{\circ}$ & 30 & yes & no & 3-D domain \\
\hline Continent & $512 \times 1 \times 256$ & $30^{\circ}$ & 30 & yes & $2000 \times 250 \mathrm{~km}$ & - \\
\hline Suite4 & $512 \times 1 \times 256$ & $20-60^{\circ}$ & 30 & yes & $2000 \times 250 \mathrm{~km}$ & initial slab dip \\
\hline Suite5 & $512 \times 1 \times 256$ & $30^{\circ}$ & 30 & yes & $100-250 \mathrm{~km}$ & continent depth \\
\hline Suite6 & $512 \times 1 \times 256$ & $30^{\circ}$ & 30 & yes & $500-2500 \mathrm{~km}$ & continent width \\
\hline
\end{tabular}

${ }^{a}$ Mantle-wedge viscosity is reduced by a factor of 100 . 

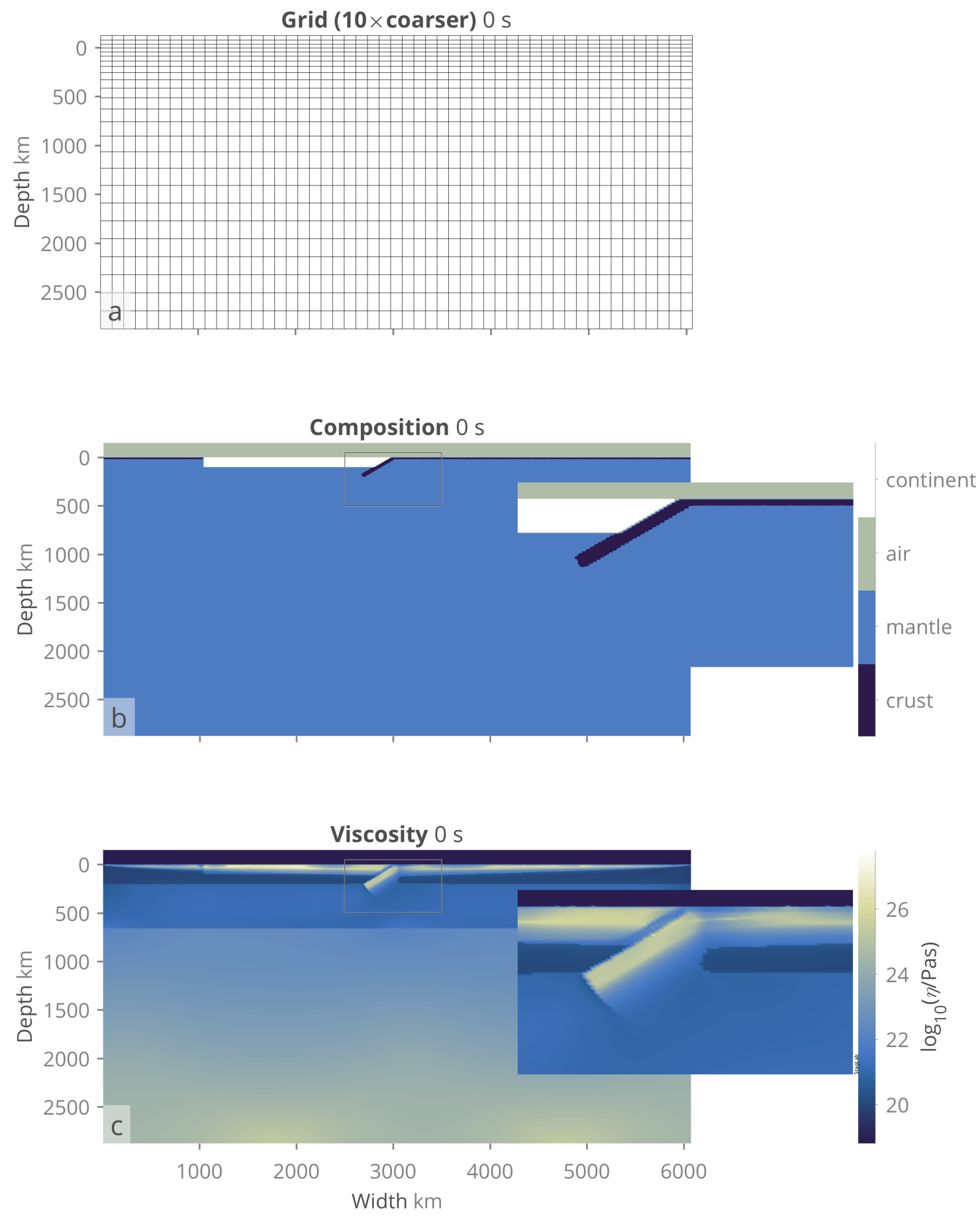

Figure 1: Initial model setup for the most complex, Continent model. (a) The $10 \times$ coarser, vertically-refined grid with periodic sides and free-slip top and bottom boundaries, (b) the initial compositional field consisting of the sticky air (yellow) enabling a free surface, reference mantle material (blue), we $e^{3}$ hydrated crust (dark blue) and continental lithosphere (white), and (c) the effective viscosity highlighting a weak asthenosphere and a high-viscosity lower mantle. 

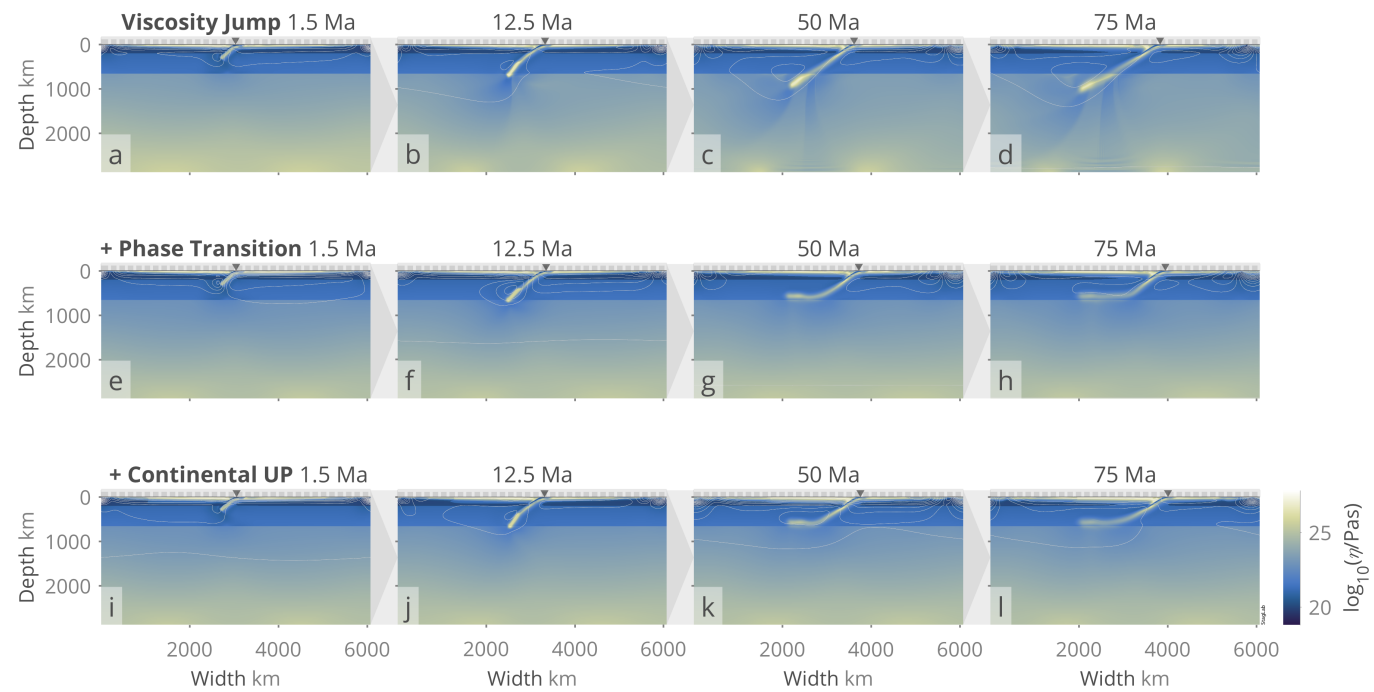

Figure 2: Time-evolution (from left to right) comparison between (a-d) the Viscosity Jump model with a simple UM-LM viscosity jump, (e-h) the PhaseTransition model that additionally includes an UM-LM phase transition, and (i-l) the Continent model that additionally features a continental upper plate. All experiments feature an initial shallow-slab dip of $30^{\circ}$ and shown is the effective viscosity with grey lines indicating flow direction. 

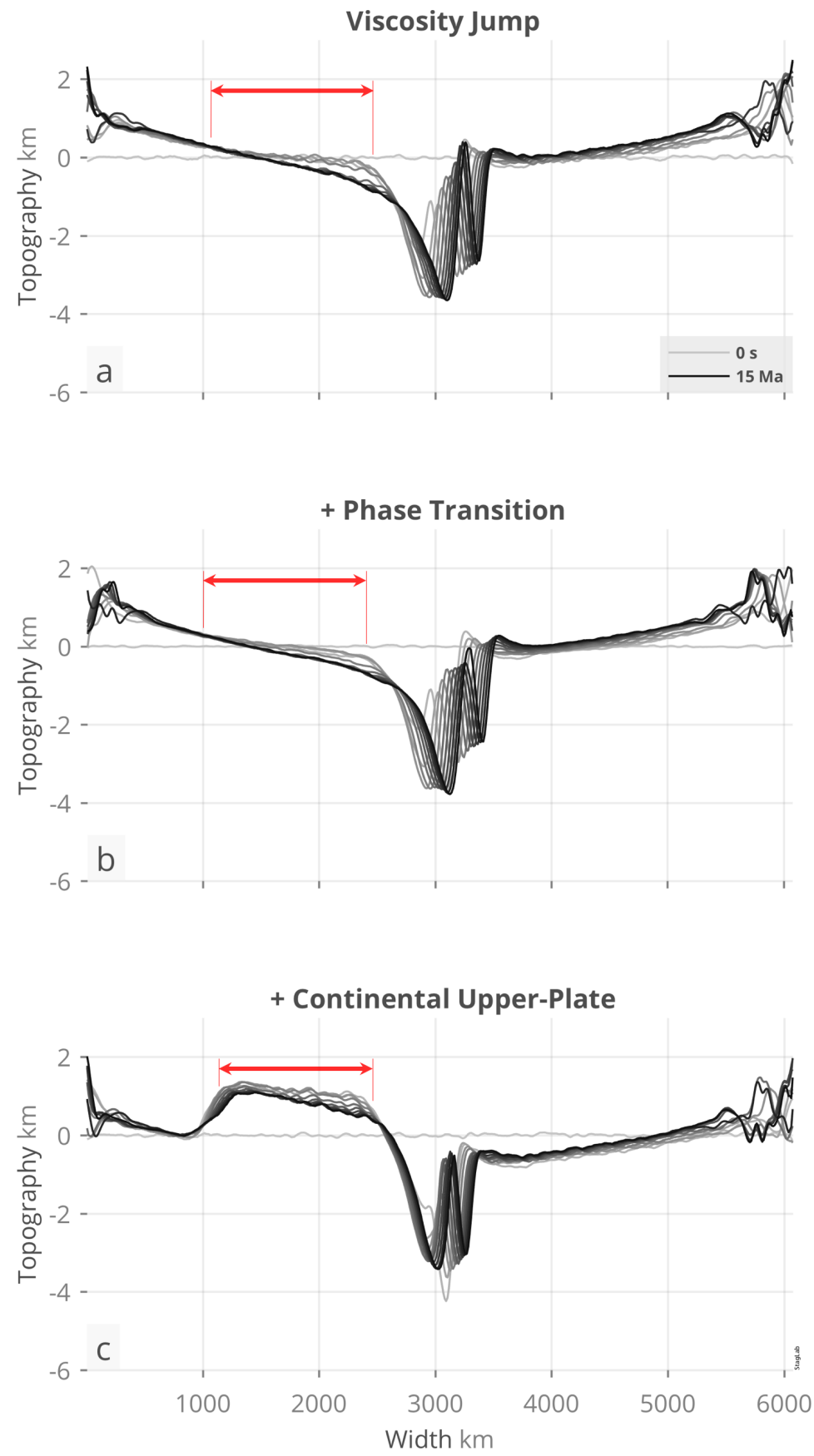

Figure 3: Time-evolution of surface topography from 0 Ma (light grey) to $15 \mathrm{Ma}$ (black) in 1.5 Ma intervals highlighting the sudden upper-plate tilt due to slab-transition-zone interaction for (a) the ViscosityJump model with a simple UM-LM viscosity jump, (b) the PhaseTransition model that additionally includes an UM-LM phase transition, and (c) the Continent model that additionally features a continental upper plate. The approximate distance over which the upper plate tilts is marked by the red indicators. All experiments feature an initial shallow-slab dip of $30^{\circ}$. 

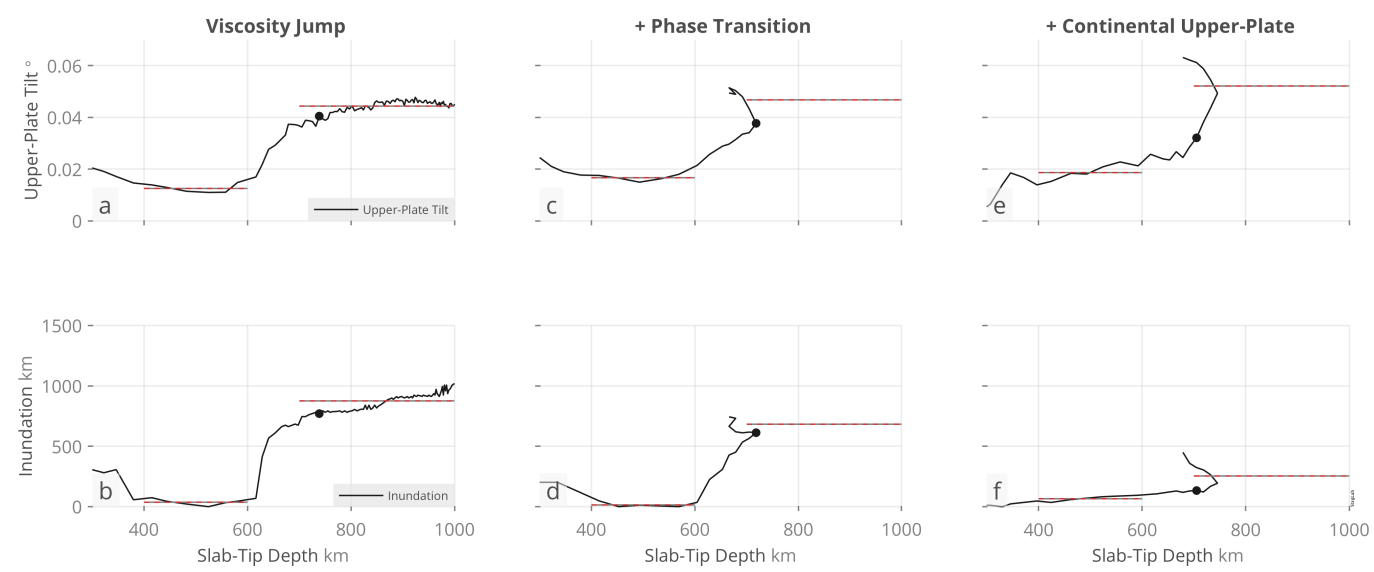

Figure 4: Upper-plate tilt (absolute) and artificial inundation (normalised to temporal minimum value) during slab-transition-zone interaction. Both upper-plate tilt (top row) and artificial inundation (bottom row) are displayed as a function of slab-tip depth and shown for (a,b) the Viscosity Jump model with a simple UM-LM viscosity jump, (c,d) the PhaseTransition model that additionally includes an UM-LM phase transition, and (e,f) the Continent model that additionally features a continental upper plate. Black points indicate $12.5 \mathrm{Ma}$ and red-grey dashed lines indicate the corresponding mean values before (i.e., over the slab-tip depth range of $400-600 \mathrm{~km}$ depth) and after slab-transition-zone collision (i.e., over the slab-tip depth range of $700-1000 \mathrm{~km}$ ). 

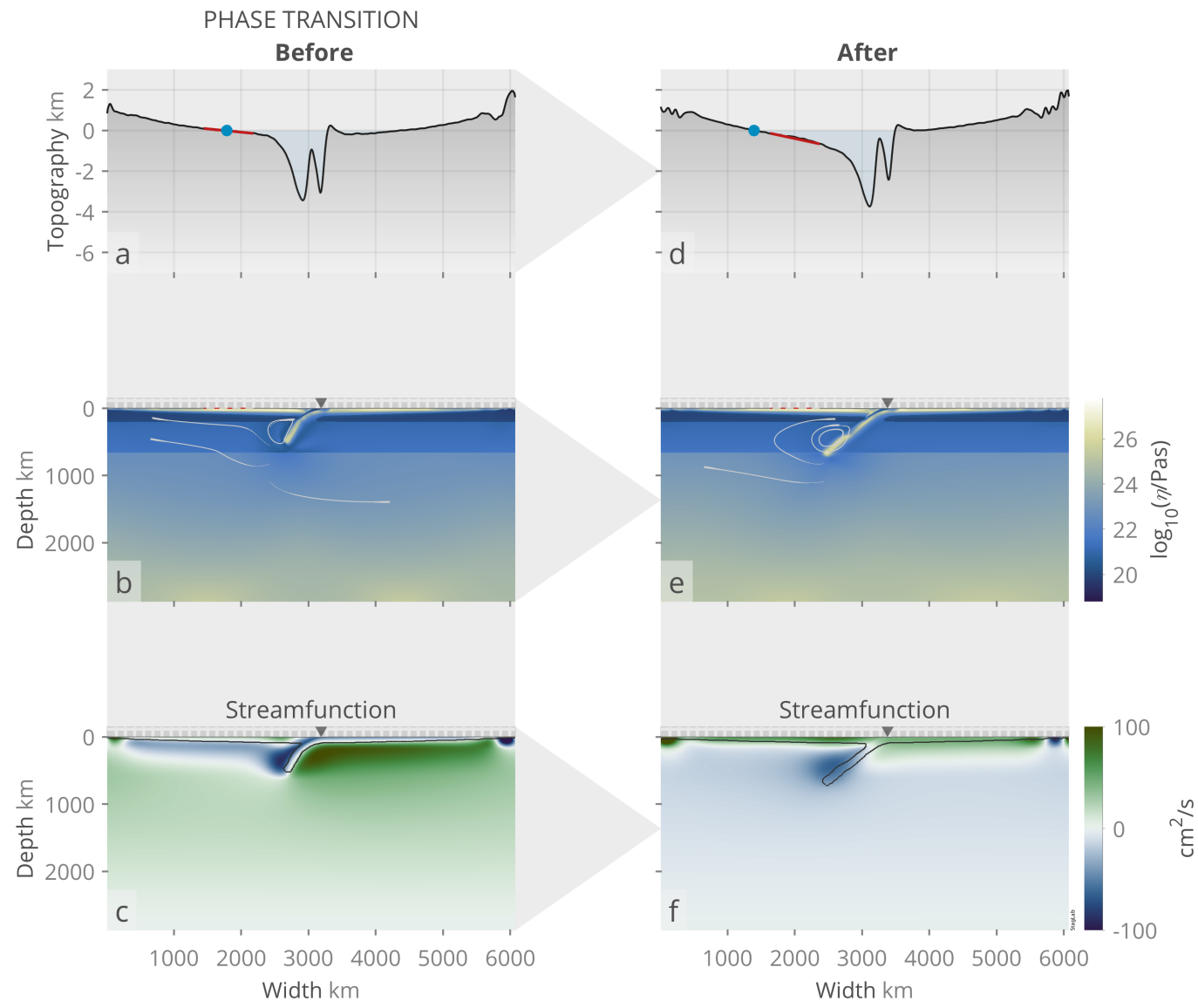

Figure 5: Comparison between (a-c) before and (d-f) after slab-transition-zone interaction for the PhaseTransition model that additionally includes an UM-LM phase transition. Shown are $(\mathrm{a}, \mathrm{d})$ surface topography with indicators for upper-plate tilt (red bar) and inundation (blue dot), (b,e) effective viscosity with grey stream lines indicating flow direction, $(c, f)$ the stream function where blue colours indicate clock-wise direction of the flow and the black contour indicates the position of the plate and slab. 

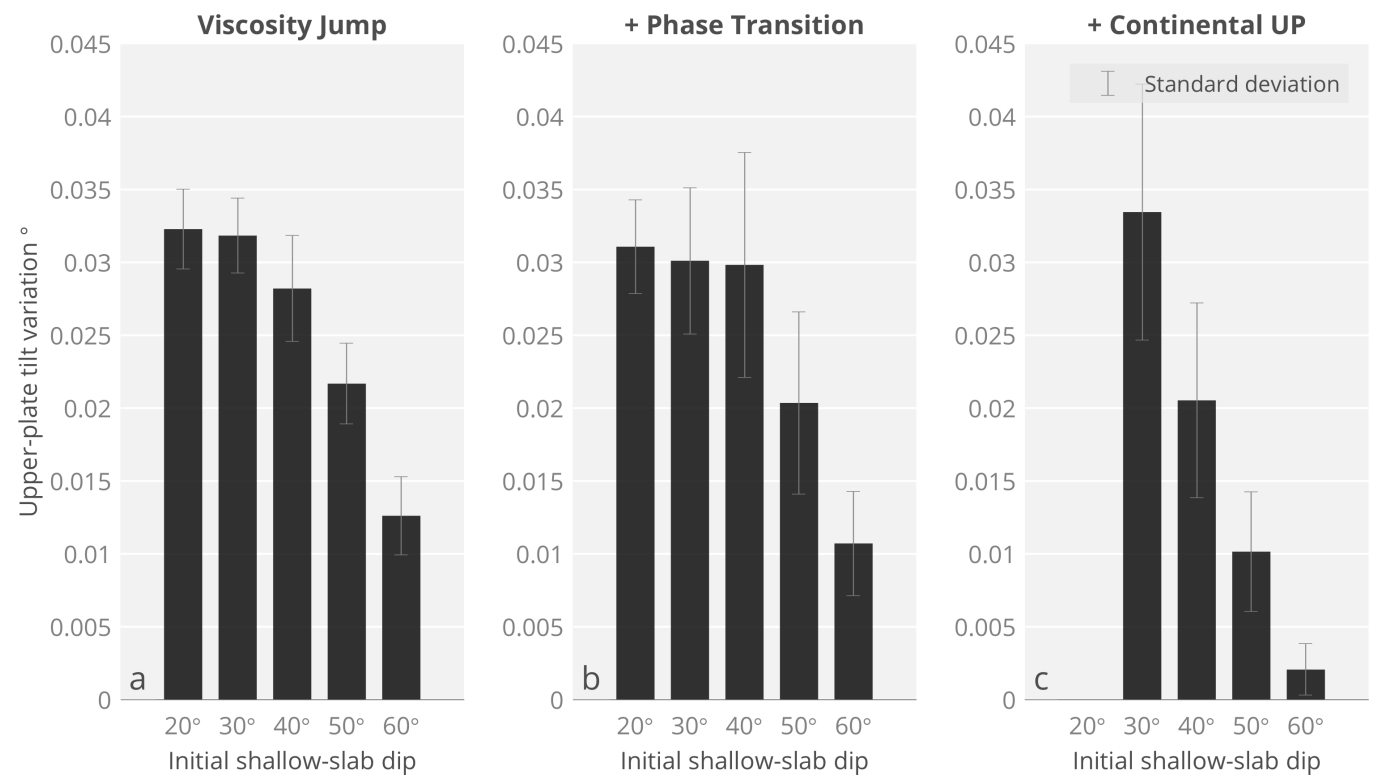

Figure 6: Mean variation (i.e., increase) in upper-plate tilt between before and after the slab-transition-zone interaction. The UP-tilt mean values are taken over a slab-depth range of $400-600 \mathrm{~km}$ and $700-1000 \mathrm{~km}$ (indicated as red-grey dashed horizontal lines in Figure 4). Compared are the three suites of model setups, (a) the ViscosityJump, (b) the PhaseTransition, and (c) the Continent model. Individual bars show the corresponding tilt-variation for experiments with variable initial shallow-slab dips ranging between $20^{\circ}$ and $60^{\circ}$. Grey indicators highlight the standard deviation related to the mean tilt values. The tilt variation in panel (c) for $20^{\circ}$ is strongly biased due to the strong coupling of the shallow slab with the thick continental upper plate (see Section 4 for more details) and therefore not shown. 

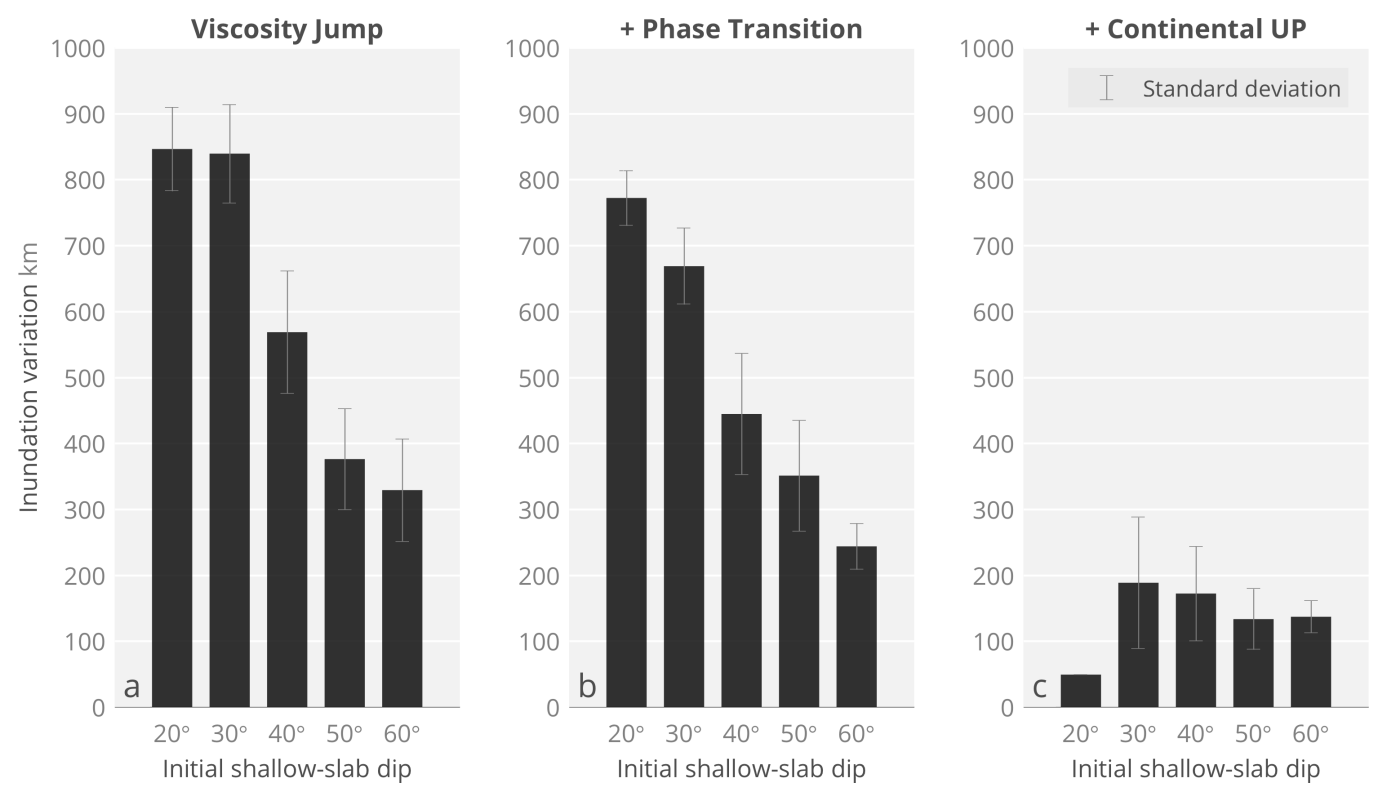

Figure 7: Mean variation (i.e., increase) in inundation between before and after the slabtransition-zone interaction. The inundation mean values are taken over a slab-depth range of $400-600 \mathrm{~km}$ and $700-1000 \mathrm{~km}$ (indicated as red-grey dashed horizontal lines in Figure 4). Compared are the three suites of model setups, (a) the ViscosityJump, (b) the PhaseTransition, and (c) the Continent model. Individual bars show the corresponding tilt-variation for experiments with variable initial shallow-slab dips ranging between $20^{\circ}$ and $60^{\circ}$. Grey indicators highlight the standard deviation related to the mean inundation values. The inundation variation in panel (c) for $20^{\circ}$ is strongly biased due to the strong coupling of the shallow slab with the thick continental upper plate (see Section 4 for more details). 

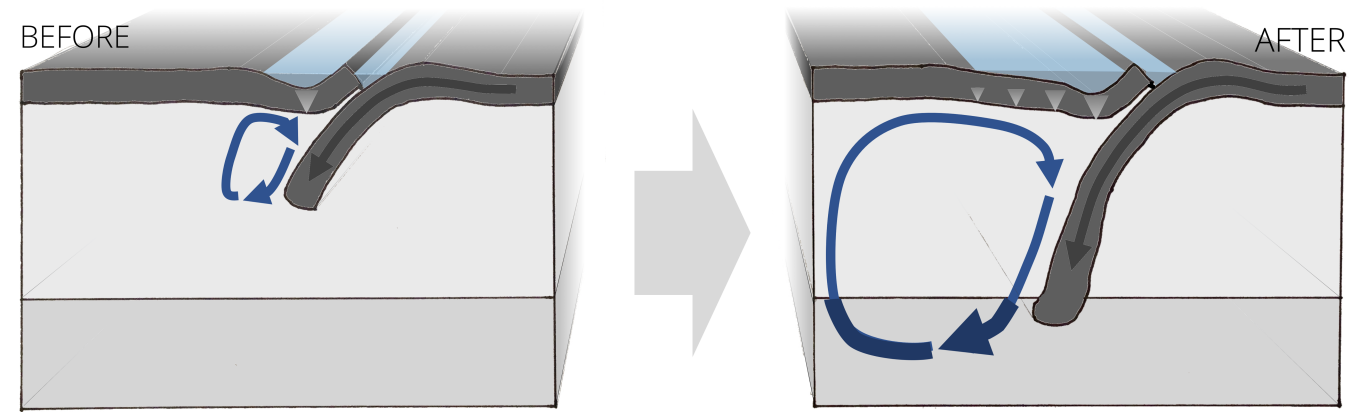

Figure 8: Schematic illustration comparing the flow dynamics before and after slabtransition-zone interaction. The left panel indicates an incipient subduction zone before slab-transition-zone interaction with only small-scale subduction-induced mantle flow, and no large-scale upper plate tilt. The right panel indicates a mature subduction zone after slab-transition-zone interaction and resulting excitation of the high-viscosity lower mantle which leads to a significantly larger, subduction-induced mantle return flow cell. The onset of the large-scale mantle flow causes an abrupt increase in continental-scale upper-plate tilt and inundation. 


\title{
Auxiliary material for \\ Dynamic Mantle-Transition-Zone Controls on Upper-Plate Tilt
}

\author{
Fabio Crameri ${ }^{1}$ and Carolina Lithgow-Bertelloni ${ }^{2}$ \\ ${ }^{1}$ Centre for Earth Evolution and Dynamics (CEED), University of Oslo, Norway. \\ ${ }^{2}$ Department of Earth Sciences, University College London, United Kingdom.
}

Tectonophysics, 2017

\section{Contents}

S1 Supplementary Movie 


\section{S1 Supplementary Movie}

The movie shows the time-evolution comparison between (a-c) the Viscosity Jump model with a simple UMLM viscosity jump, (d-f) the PhaseTransition model that additionally includes an UM-LM phase transition, and (g-i) the Continent model that additionally features a continental upper plate. All experiments feature an initial shallow-slab dip of $30^{\circ}$ and shown are a graph of slab-tip depth versus upper-plate tilt with a white dot indicating current time (top row), current surface topography (middle row), and current effective viscosity (bottom row). Red lines indicate the automated tracking of the upper-plate tilt.

\section{S2 Supplementary Figures}

See figures and corresponding captions below. 

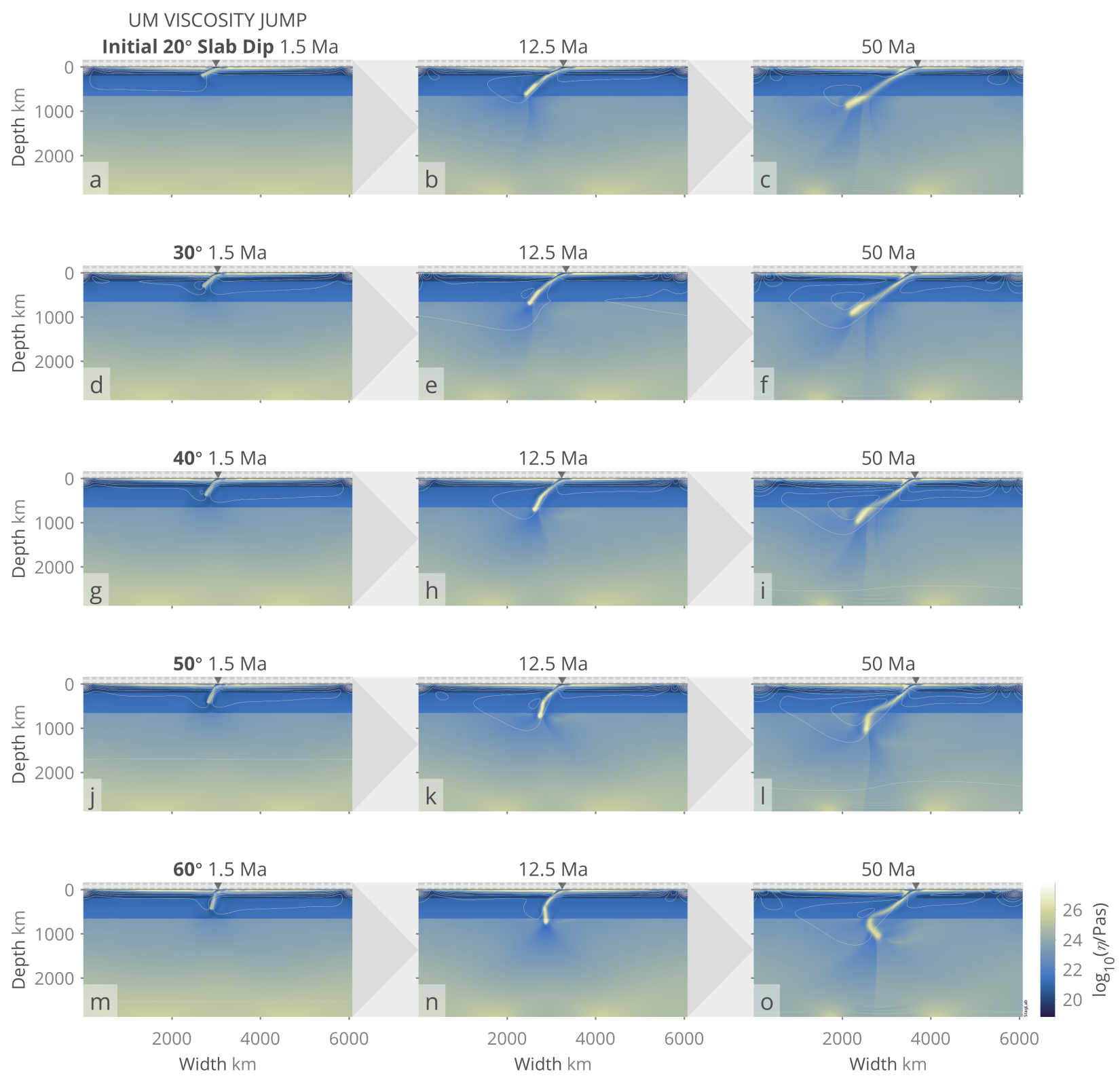

Figure S1: Time evolution (from left to right) of the ViscosityJump model with a simple UM-LM viscosity jump for multiple experiments with different initial shallow slab-dip angles ranging from (a-c) $20^{\circ}$ to (m-p) $60^{\circ}$. Shown is the effective viscosity and grey lines indicate flow direction. 

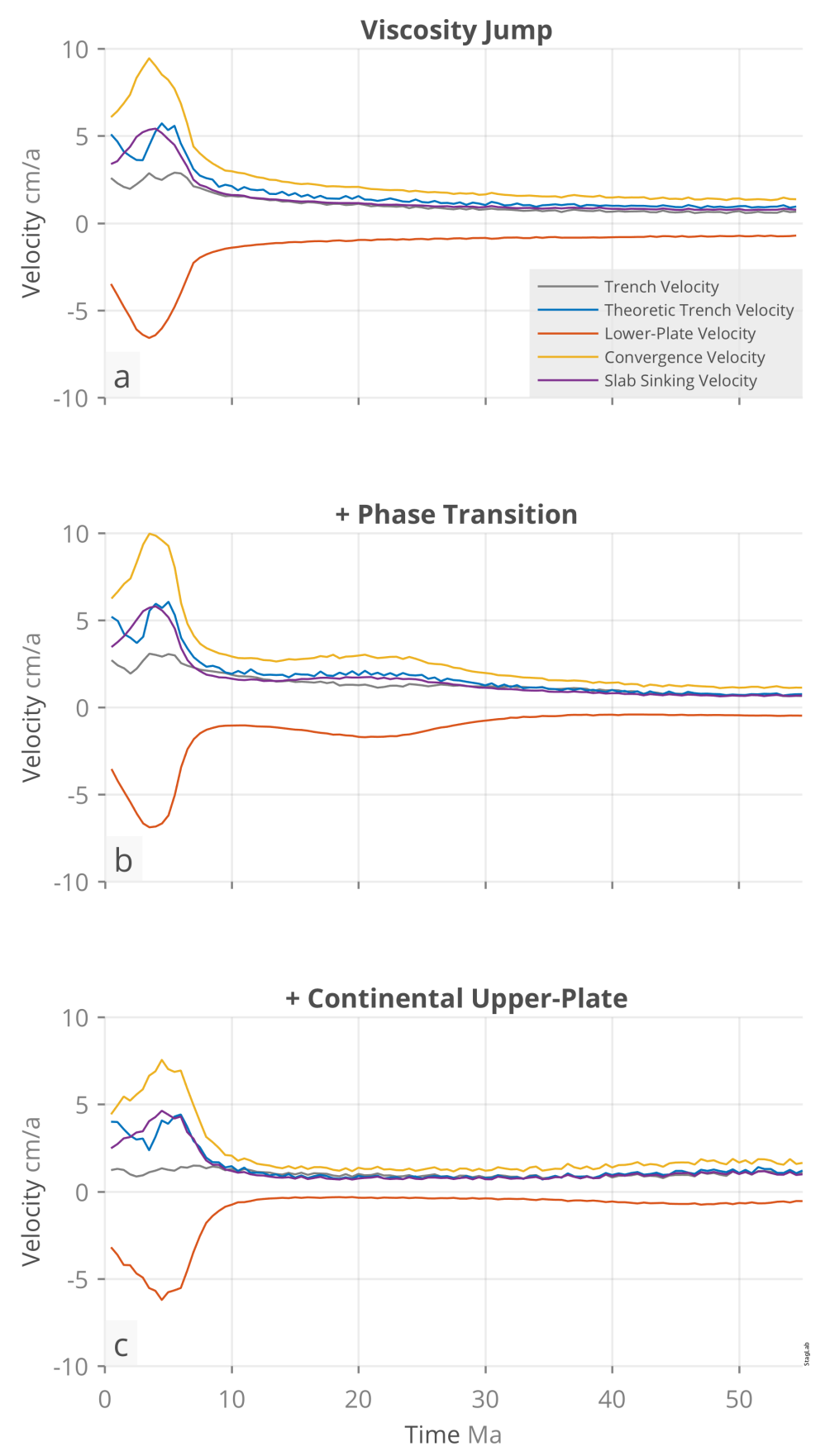

Figure S2: Plate-velocity graph for (a) the ViscosityJump model with an UM-LM viscosity jump of factor 100 but no phase transition, (b) the PhaseTransition model with an UM-LM viscosity jump of factor 30 and an upper-mantle phase transition, and (c) the Continent model with a phase transition and a 2000-km wide continental upper-plate. All models have an initial $30^{\circ}$ shallow-slab dip angle. Shown are effective and theoretic trench velocities, lower-plate velocity, slab-sinking velocity, and total plate-convergence velocity. 


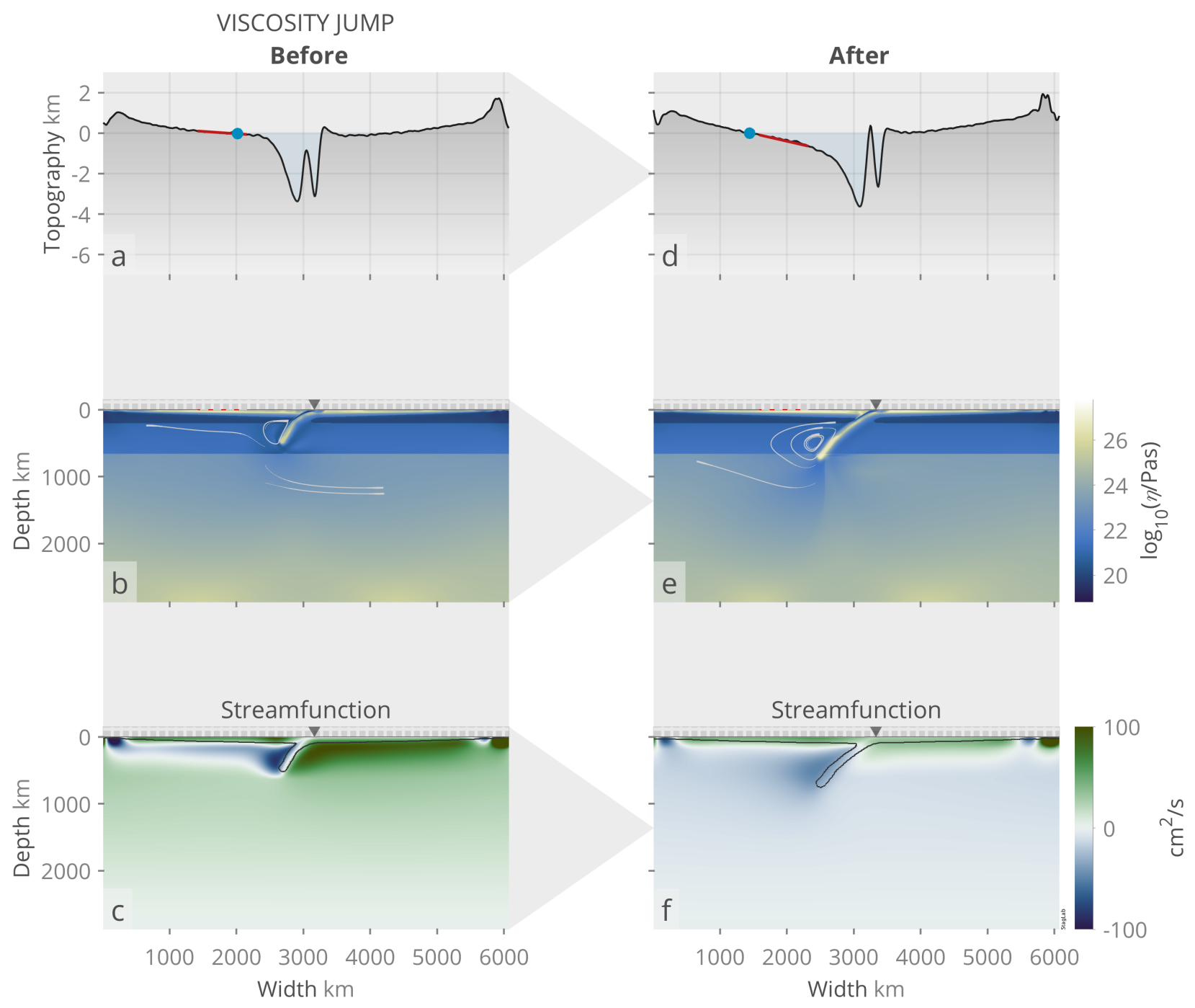

Figure S3: Comparison between (a-c) before and (d-f) after slab-transition zone interaction for the ViscosityJump model with a simple UM-LM viscosity jump. Shown are (a,d) surface topography with indicators for upper-plate tilt (red bar) and inundation (blue dot), (b,e) effective viscosity with grey lines indicating flow direction, $(\mathrm{c}, \mathrm{f})$ the stream function where blue colours indicate clock-wise direction of the flow and the black contour indicates the position of the plate and slab. 

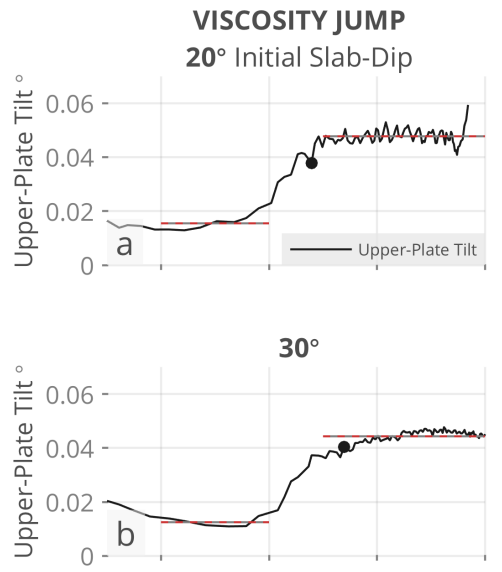

$40^{\circ}$
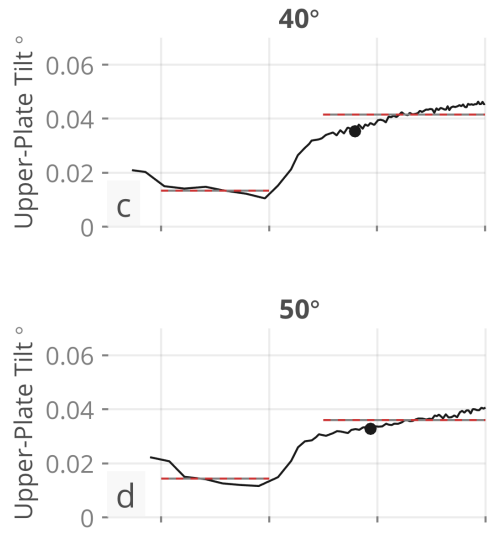

$60^{\circ}$

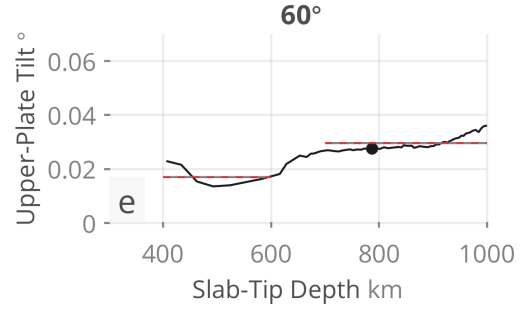

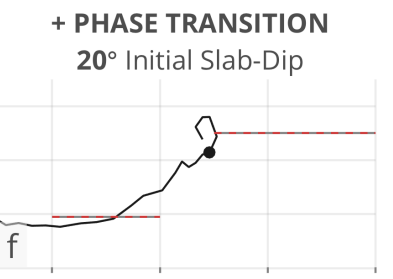

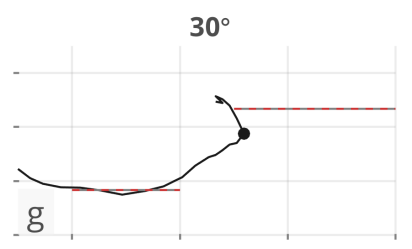

$40^{\circ}$

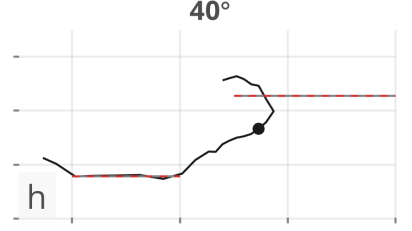

$50^{\circ}$

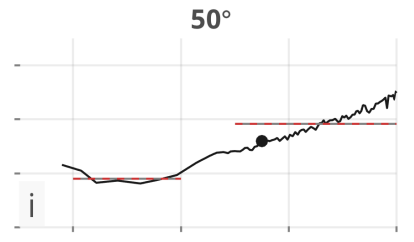

$60^{\circ}$

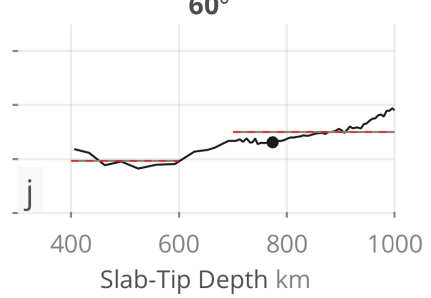

+ CONTINENTAL UP

20 Initial Slab-Dip
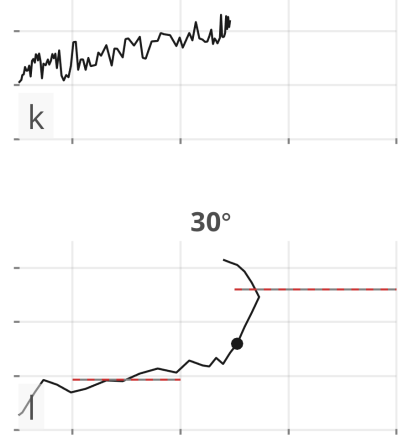

$40^{\circ}$
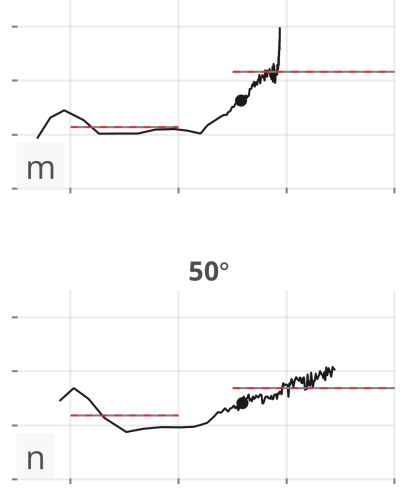

$60^{\circ}$

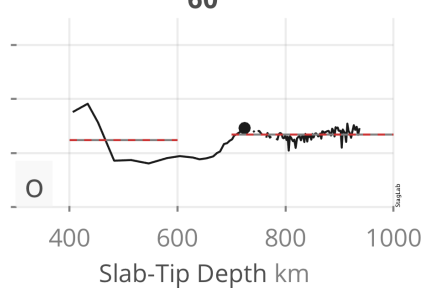

Figure S4: Upper-plate tilt as a function of slab-tip depth shown for (a-e) the ViscosityJump, (f-j) the PhaseTransition, and (k-o) the Continent model setup with variable initial shallow-slab dips ranging between $(\mathrm{a}, \mathrm{f}, \mathrm{k}) 20^{\circ}$ and $(\mathrm{e}, \mathrm{j}, \mathrm{o}) 60^{\circ}$. Black points indicate $12.5 \mathrm{Ma}$ and red-grey dashed lines indicate the mean tilt-values during slab-tip sinking between $400-600 \mathrm{~km}$ depth (i.e., before slab-transition zone interaction) and from the point the slab reaches $700 \mathrm{~km}$ depth (i.e., after slab-transition zone collision) to a maximum of $1000 \mathrm{~km}$ depth (if reached). The UP-tilt in panel (k) for $20^{\circ}$ is strongly biased due to the strong coupling of the shallow slab with the thick continental upper plate (see Section 4 for more details). 

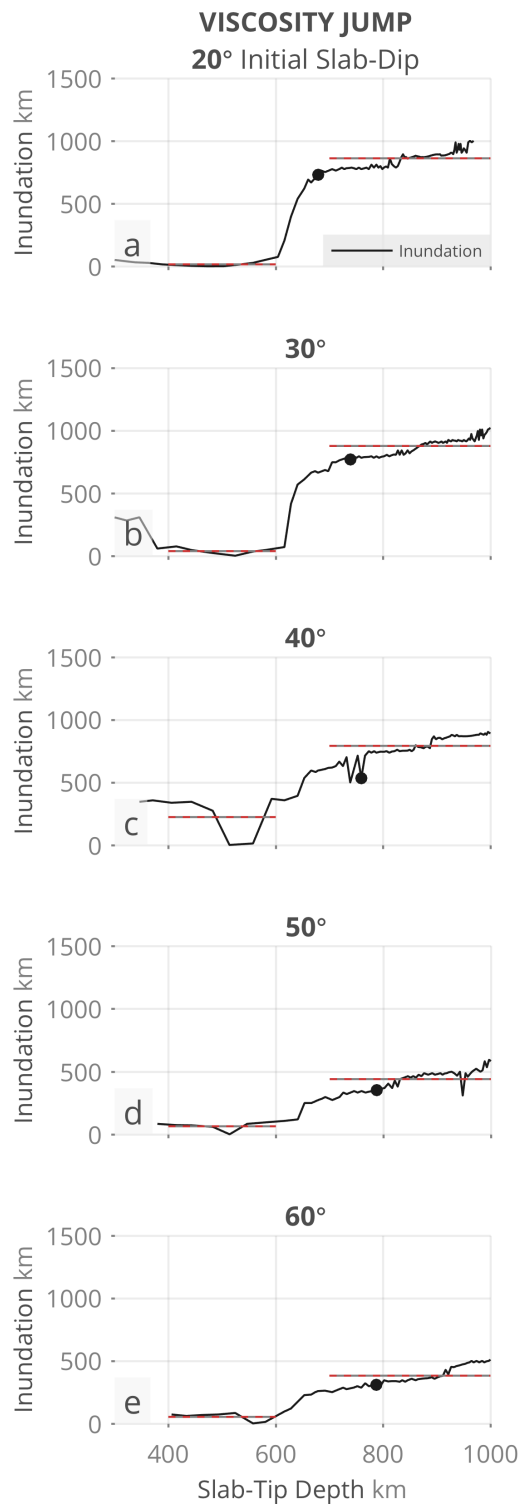

+ PHASE TRANSITION

$20^{\circ}$ Initial Slab-Dip

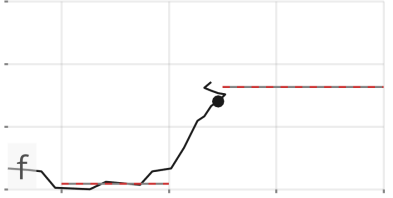

$30^{\circ}$

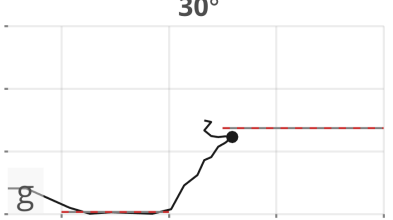

$40^{\circ}$

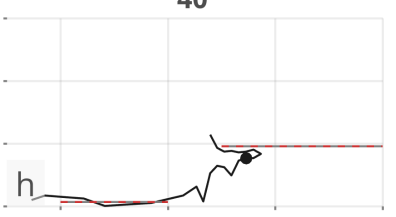

$50^{\circ}$

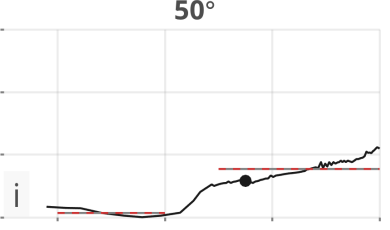

$60^{\circ}$

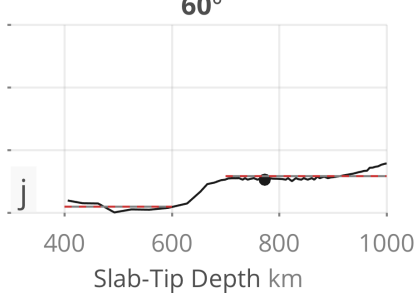

+ CONTINENTAL UP

$20^{\circ}$ Initial Slab-Dip

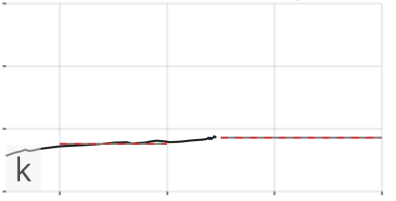

$30^{\circ}$

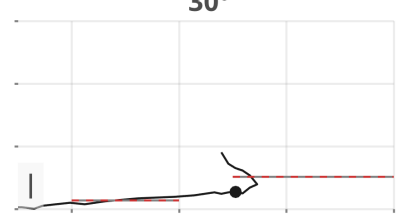

$40^{\circ}$

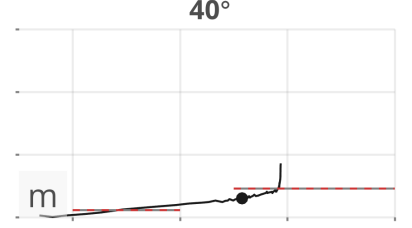

$50^{\circ}$

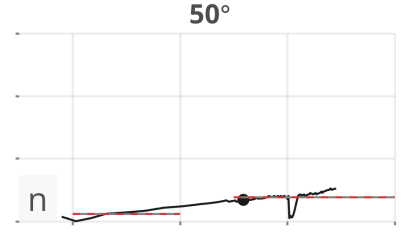

$60^{\circ}$

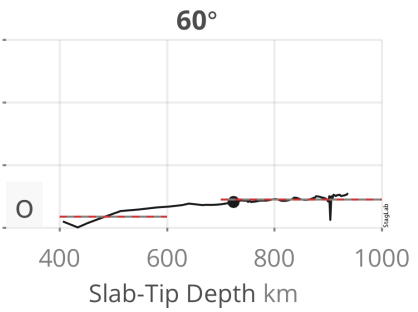

Figure S5: Inundation (normalised to temporal minimum value) as a function of slab-tip depth shown for (ae) the Viscosity Jump, (f-j) the PhaseTransition, and (k-o) the Continent model setup with variable initial shallow-slab dips ranging between $(\mathrm{a}, \mathrm{f}, \mathrm{k}) 20^{\circ}$ and $(\mathrm{e}, \mathrm{j}, \mathrm{o}) 60^{\circ}$. Black points indicate $12.5 \mathrm{Ma}$ and red-grey dashed lines indicate the mean tilt-values during slab-tip sinking between $400-600 \mathrm{~km}$ depth (i.e., before slab-transition zone interaction) and from the point the slab reaches $700 \mathrm{~km}$ depth (i.e., after slab-transition zone collision) to a maximum of $1000 \mathrm{~km}$ depth (if reached). The UP-tilt in panel (k) for $20^{\circ}$ is strongly biased due to the strong coupling of the shallow slab with the thick continental upper plate (see Section 4 for more details). 

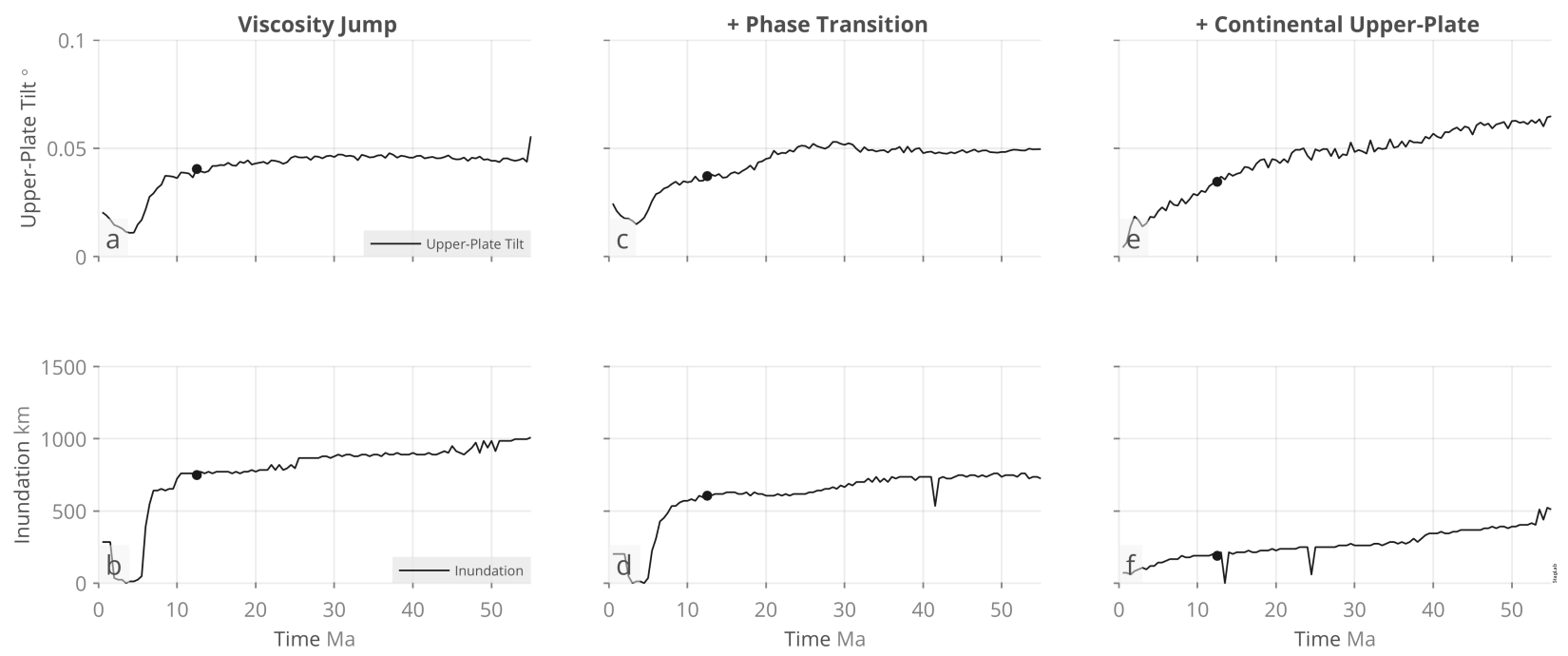

Figure S6: Temporal evolution of absolute upper-plate tilt and variation in artificial inundation during slab-transition zone interaction. Both upper-plate tilt (top row) and artificial inundation (bottom row) are displayed as a function of time and shown for $(\mathrm{a}, \mathrm{b})$ the Viscosity Jump model with a simple UM-LM viscosity jump, (c,d) the PhaseTransition model that additionally includes an UM-LM phase transition, and (e,f) the Continent model that additionally features a continental upper plate. Black points indicate 12.5 Ma and spikes are caused by rough surface portions that act as a dam that can be suddenly flooded or inhibit further inundation. 

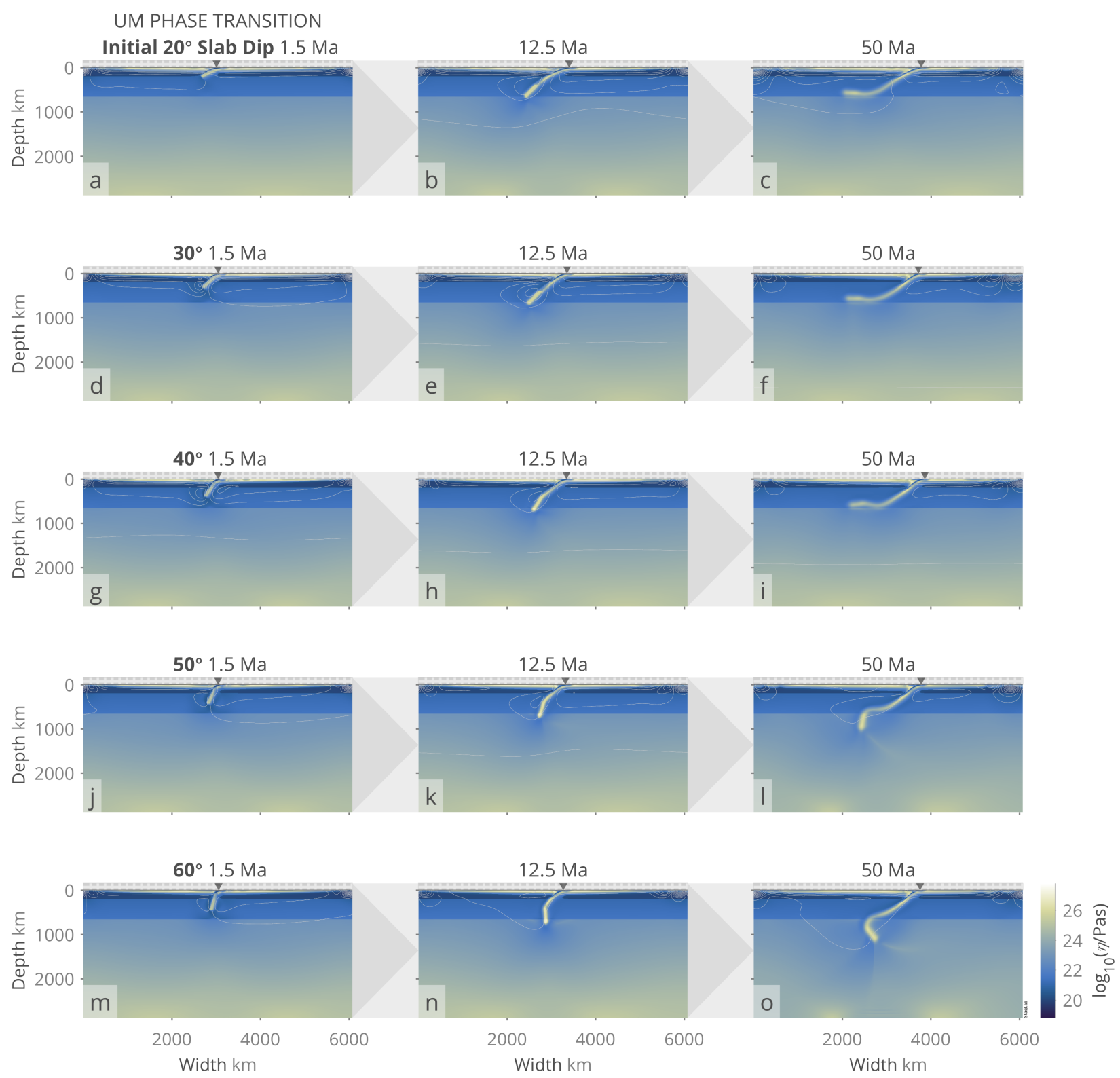

Figure S7: Time evolution (from left to right) of the PhaseTransition model for multiple experiments with different initial shallow-slab dip angles ranging from (a-c) $20^{\circ}$ to $(\mathrm{m}-\mathrm{o}) 60^{\circ}$. Shown is the effective viscosity and grey lines indicate flow direction. 

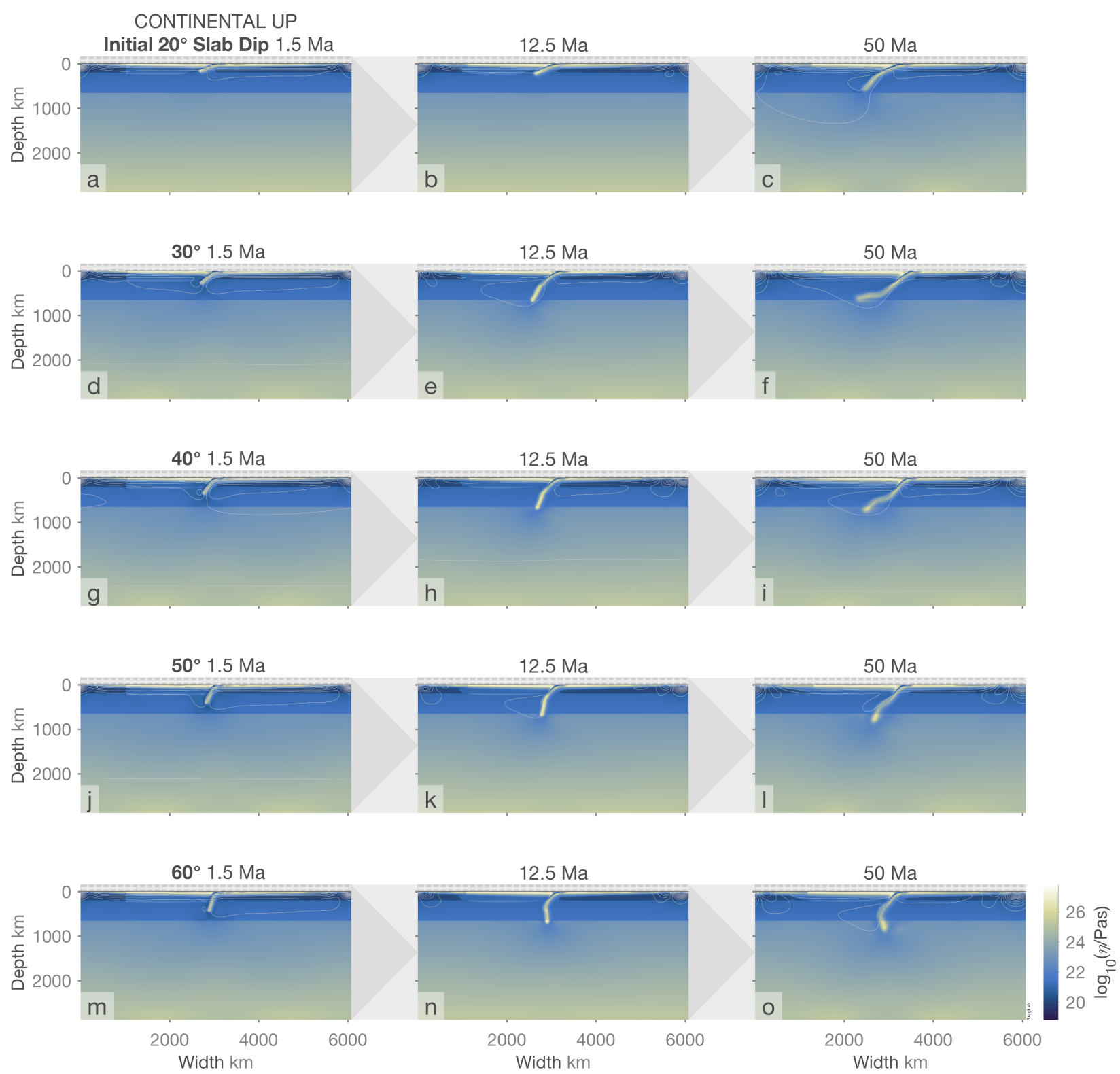

Figure S8: Time evolution (from left to right) of the Continent model with a 250-km thick and 2000-km wide continent for multiple experiments employing different initial shallow-slab dip angles ranging from $20^{\circ}$ (top row) to $60^{\circ}$ (bottom row). Shown is the viscosity and grey lines indicate flow direction. 

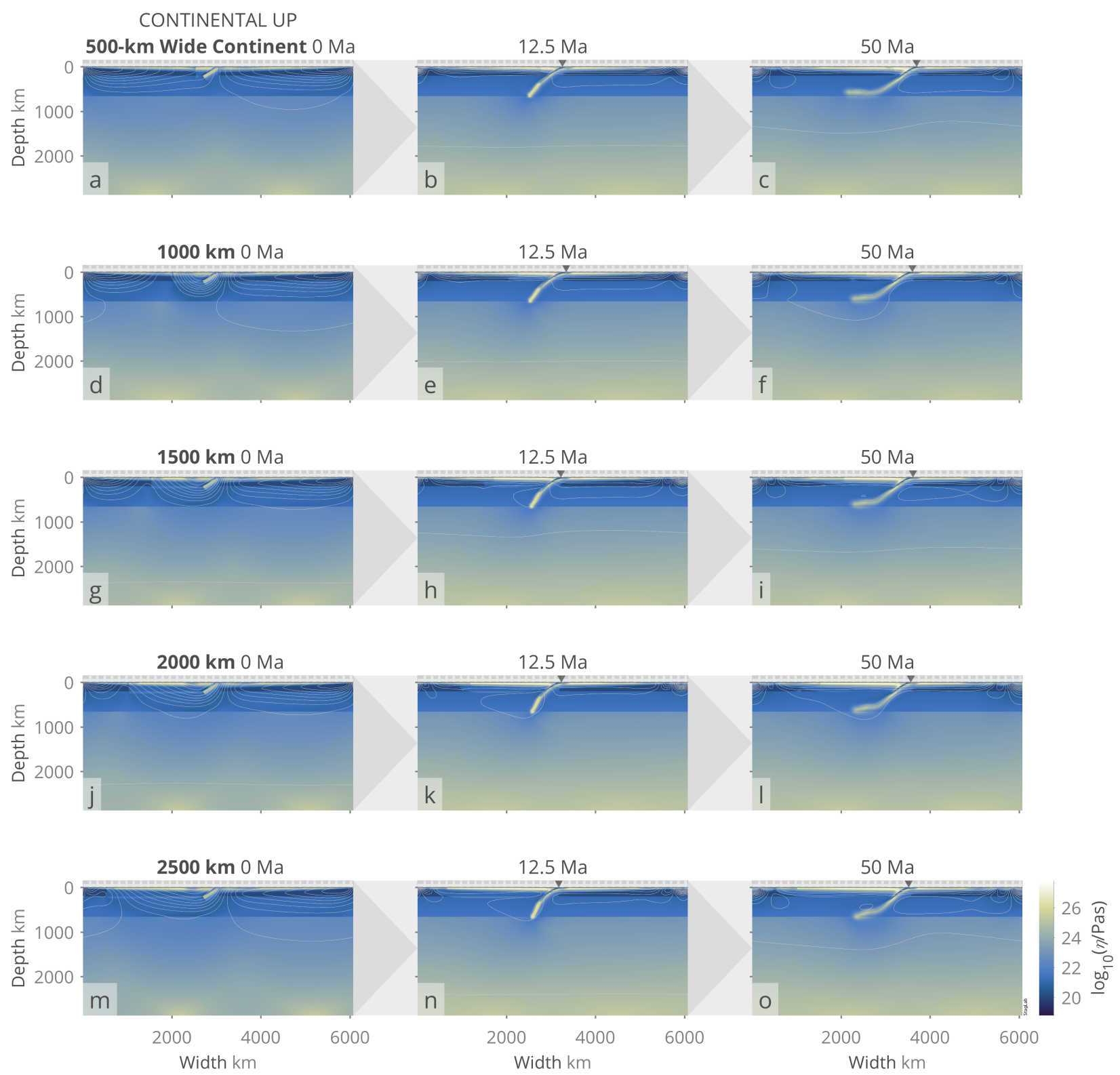

Figure S9: Time evolution (from left to right) for multiple experiments of the Continent model employing a 250-km thick and differently-wide continental upper plates ranging from $500 \mathrm{~km}$ (top row) to $2500 \mathrm{~km}$ (bottom row). Shown is the viscosity and grey lines indicate flow direction. 

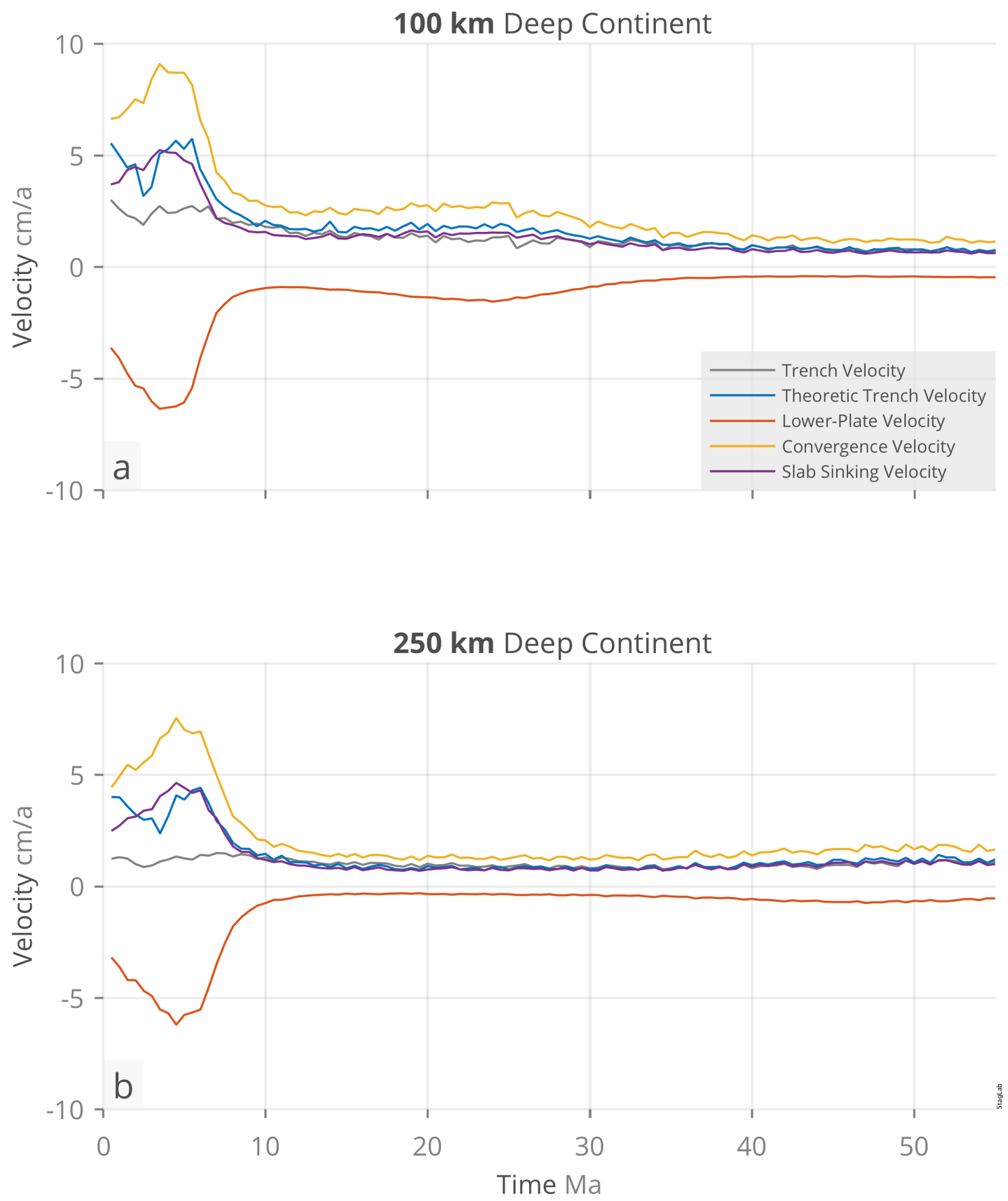

Figure S10: Plate-velocity evolution over time of two experiments of the Continent model with (a) a $100 \mathrm{~km}$ and (b) a $250 \mathrm{~km}$ thick continent. Shown are actual (blue) and theoretic (red) trench velocities, lower-plate velocity (yellow), convergence velocity (purple), and slab sinking velocity (green). 


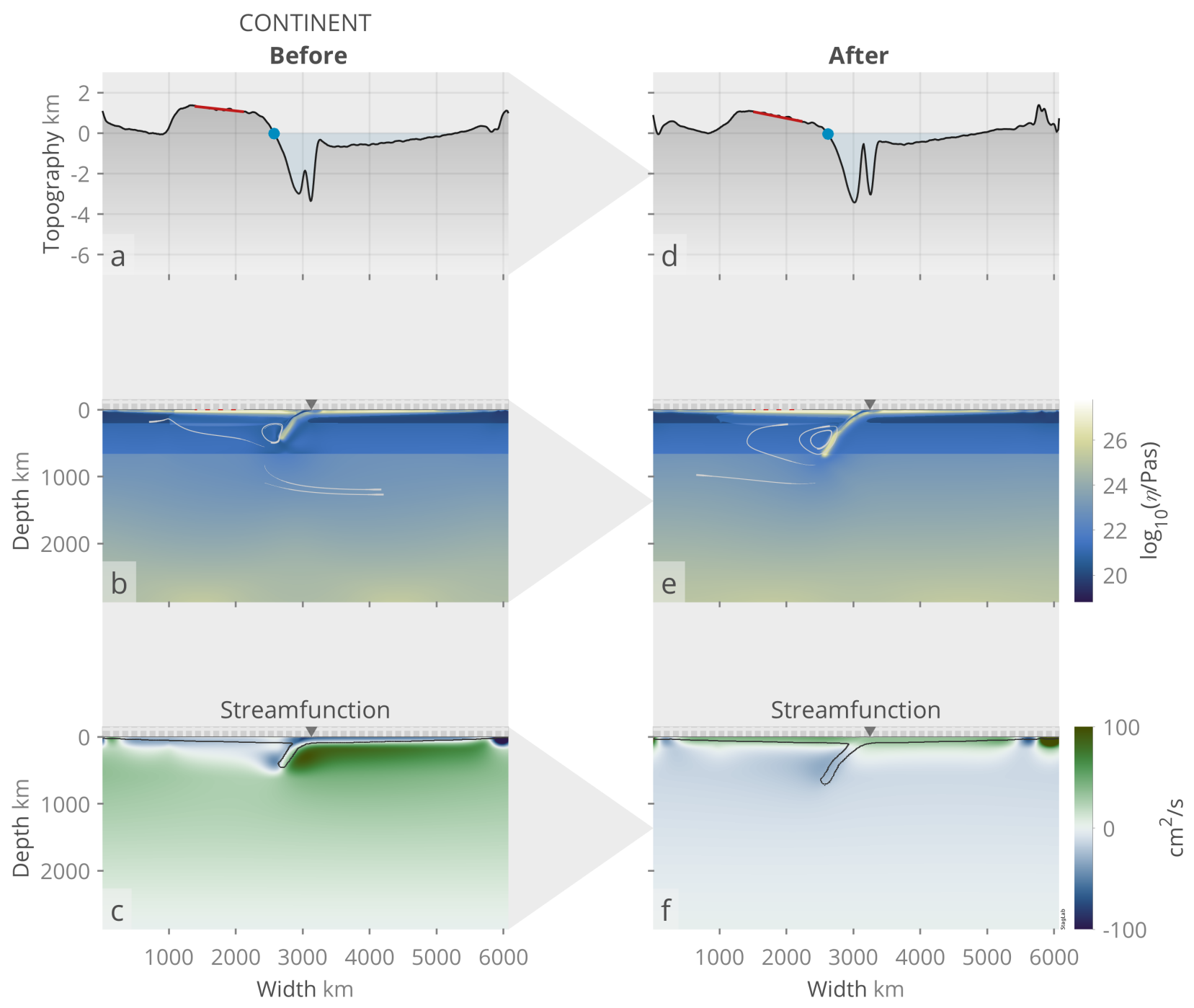

Figure S11: Comparison between (a-c) before and (d-f) after slab-transition zone interaction for the Continent model that additionally includes a continental upper plate. Shown are (a,d) surface topography with indicators for upper-plate tilt (red bar) and inundation (blue dot), (b,e) effective viscosity with grey lines indicating flow direction, (c,f) the stream function where blue colours indicate clock-wise direction of the flow and the black contour indicates the position of the plate and slab. 

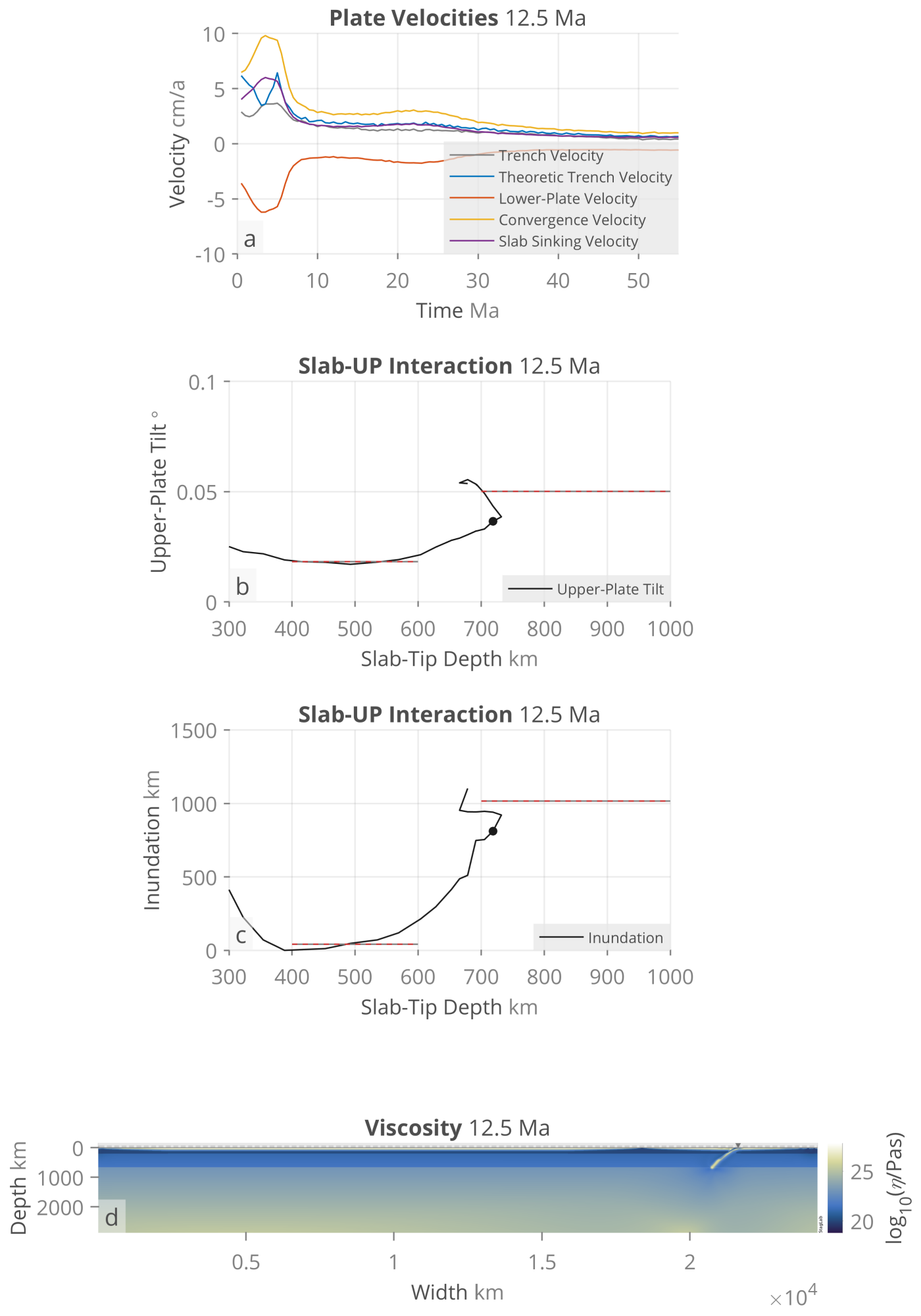

Figure S12: Model domain test: Wider aspect ratio. The PhaseTransition model in a wider 8:1 aspectratio domain for an experiment employing an initial shallow-slab dip angle of $30^{\circ}$. Shown are (a) temporal evolution of trench and plate velocities, (b) the upper-plate tilt as a function of the slab-tip depth, (c) the upper-plate inundation as a function of the slab-tip depth, and (d) the effective viscosity. Red-grey dashed lines indicate the mean values before and after slab-transition zone interaction and black dots indicate the current time step shown in (d). 

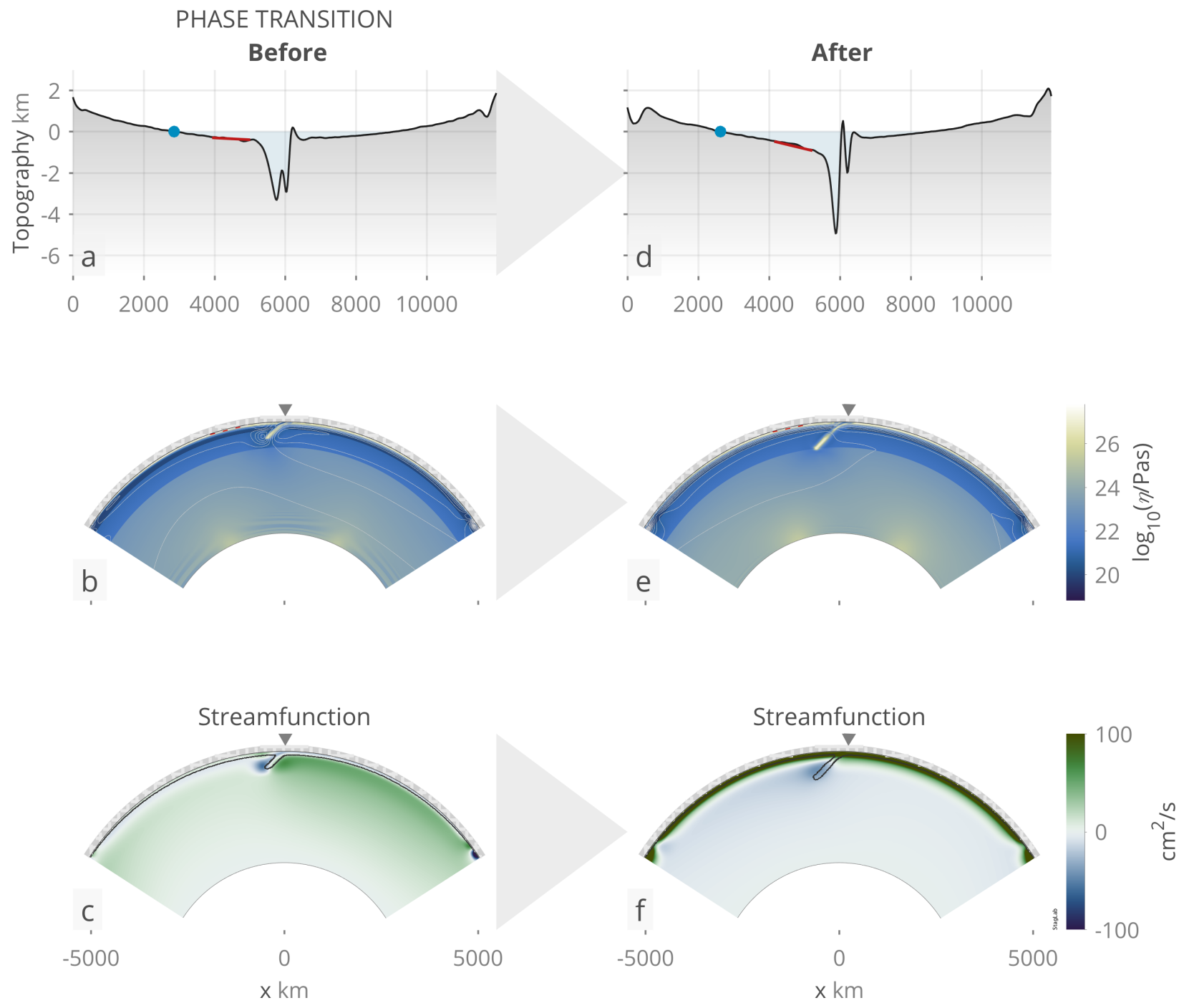

Figure S13: Model domain test: Cylindrical geometry. Comparison between (a-c) before and (d-f) after slab-transition zone interaction for the PhaseTransition model in a cylindrical domain that includes an UM-LM phase transition. Shown are (a,d) surface topography with indicators for upper-plate tilt (red bar) and inundation (blue dot), (b,e) effective viscosity with grey lines indicating flow direction, $(\mathrm{c}, \mathrm{f})$ the stream function where blue colours indicate clock-wise direction of the flow and the black contour indicates the position of the plate and slab. 

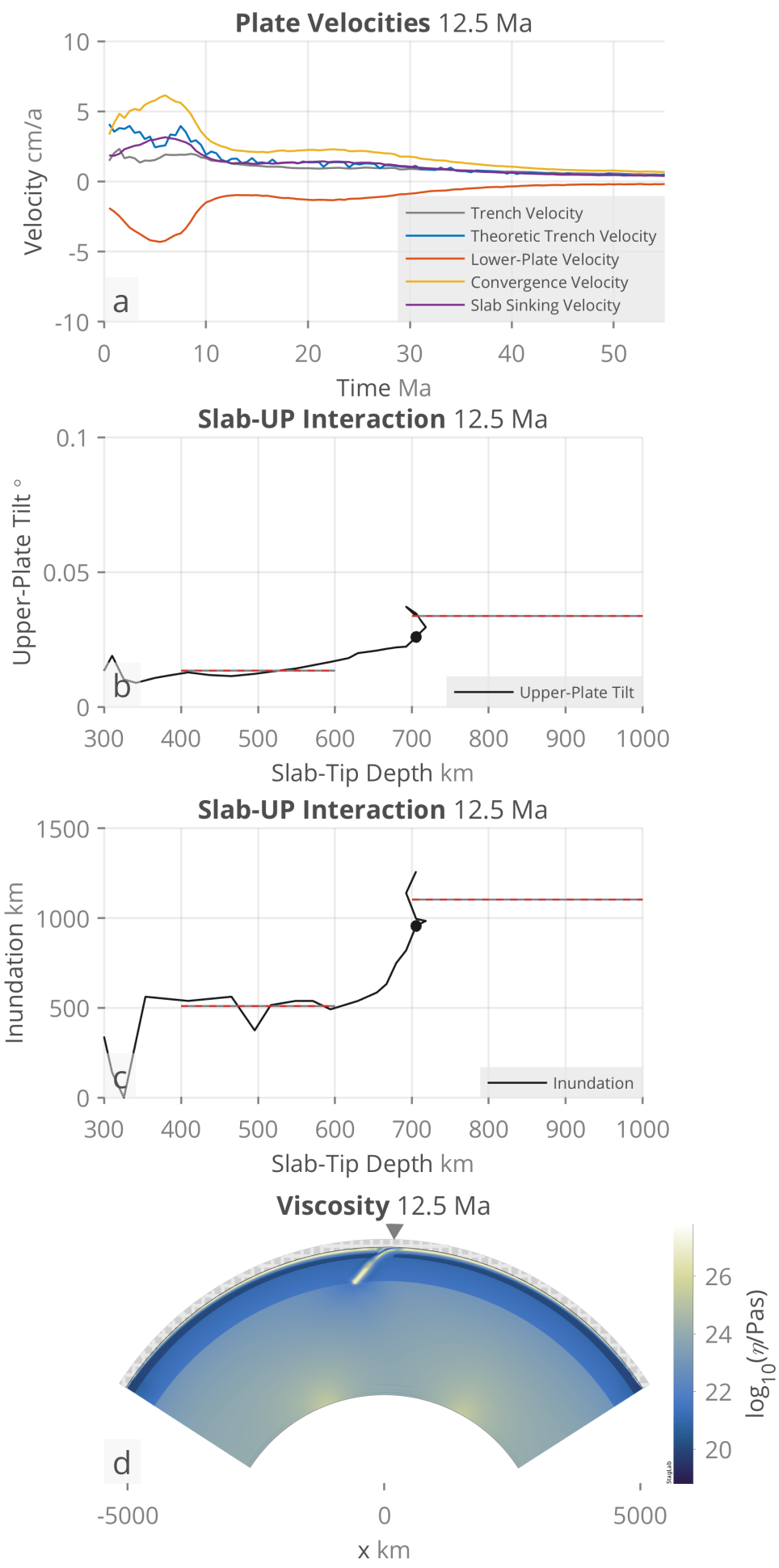

Figure S14: Model domain test: Cylindrical geometry. The PhaseTransition model in a cylindrical domain for an experiment employing an initial shallow-slab dip angle of $\sim 30^{\circ}$. Shown are (a) temporal evolution of trench and plate velocities, (b) the upper-plate tilt as a function of the slab-tip depth, (c) the upper-plate inundation as a function of the slab-tip depth, and (d) the effective viscosity. Red-grey dashed lines indicate the mean values before and after slab-transition zone interaction and black dots indicate the current time step shown in (d). 

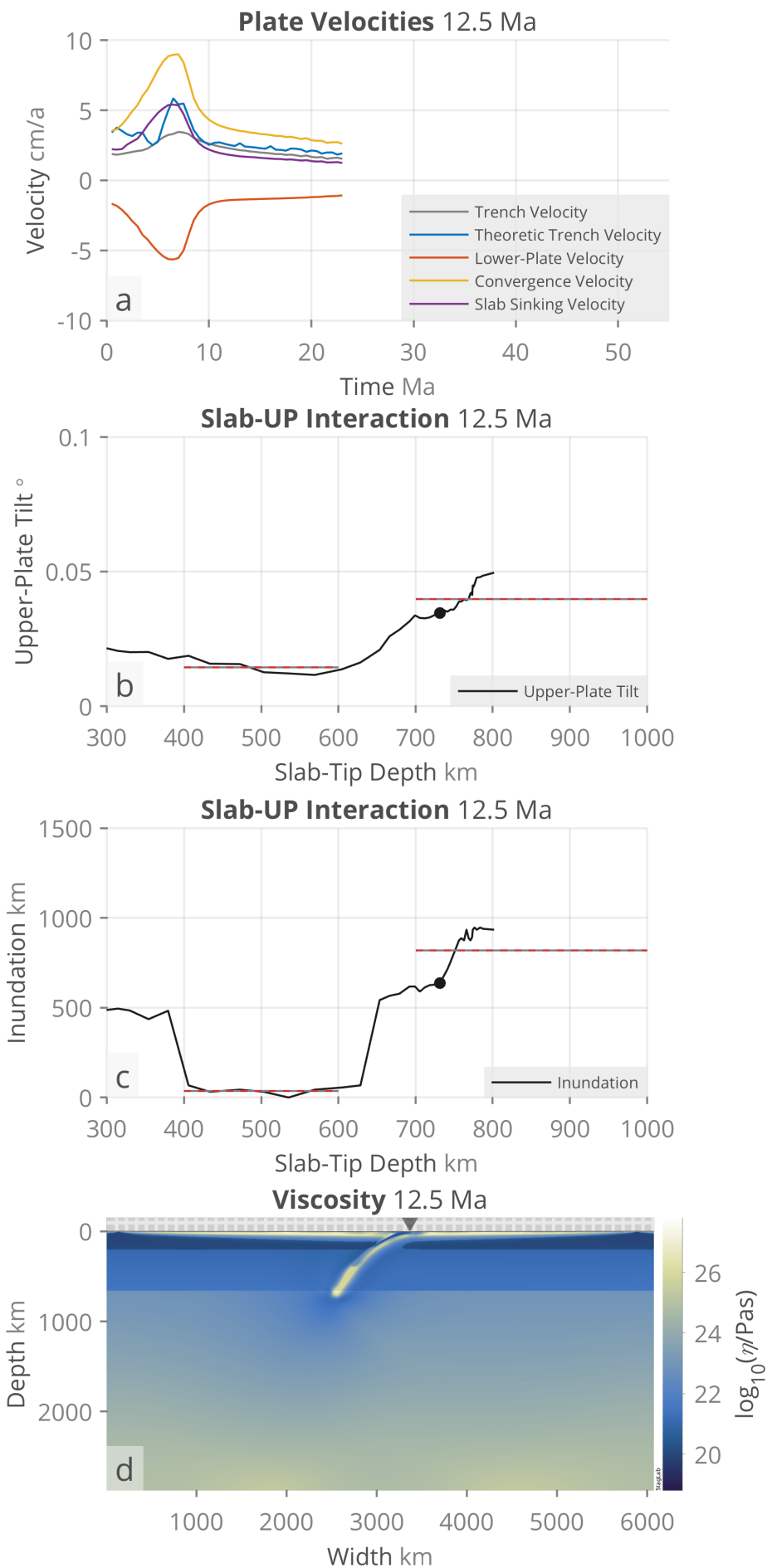

Figure S15: Model domain test: 3-D geometry. The PhaseTransition model in a 3-D geometry for an experiment employing an initial shallow-slab dip angle of $\sim 30^{\circ}$ and a lateral, effectively $100-\mathrm{km}$ wide slab gap to allow for toroidal mantle flow. Shown are (a) temporal evolution of trench and plate velocities, (b) the upper-plate tilt as a function of the slab-tip depth, (c) the upper-plate inundation as a function of the slab-tip depth, and (d) the effective viscosity on a vertical slice through the middle of the domain. Red-grey dashed lines indicate the mean values before and after slab-transition zone interaction and black dots indicate the current time step shown in (d). 

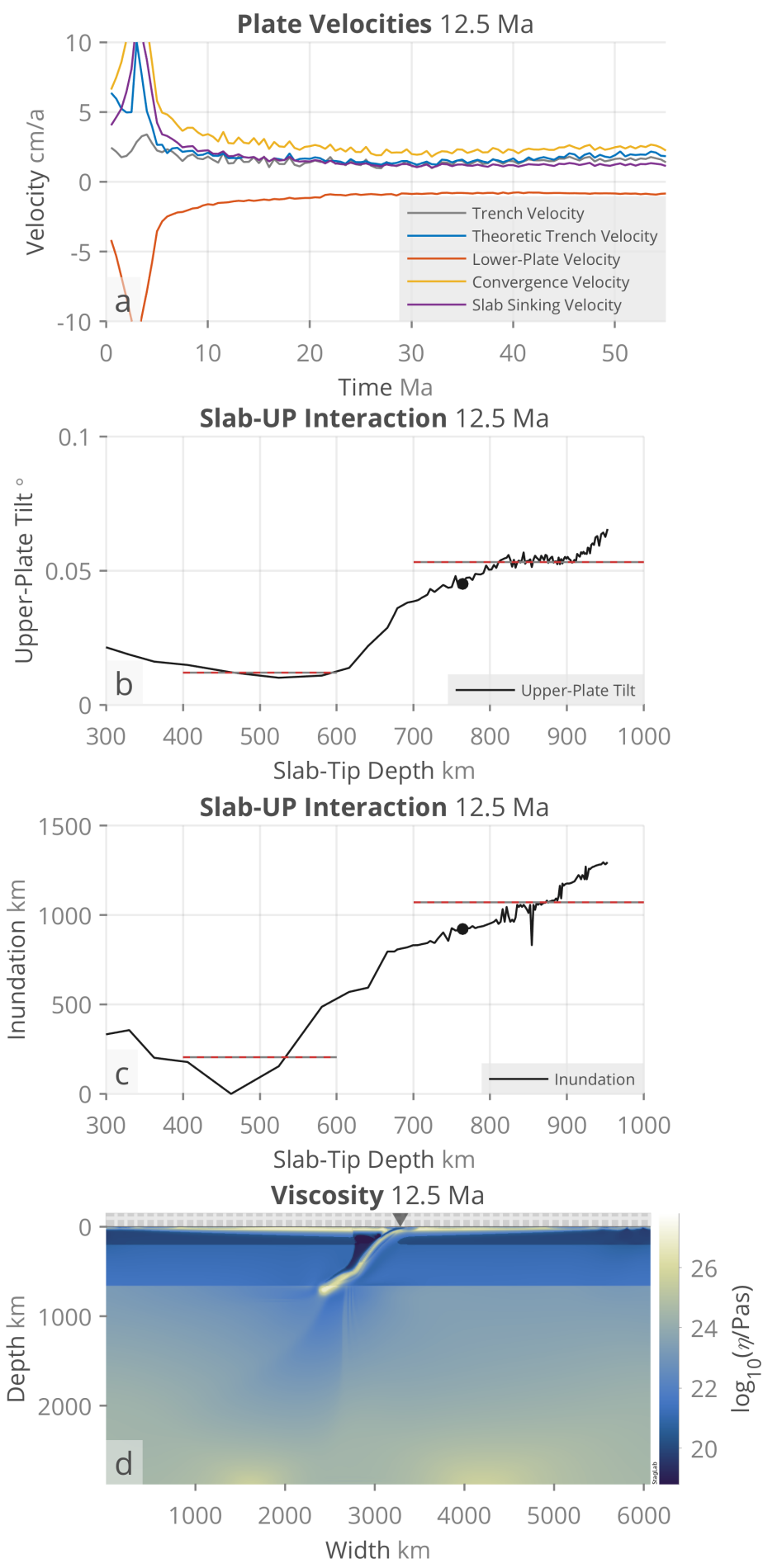

Figure S16: Rheology test: Low-viscosity mantle wedge. The ViscosityJump model with the addition of a factor of 100 lower viscosity mantle-wedge for an experiment employing an initial shallow-slab dip angle of $\sim 30^{\circ}$. Shown are (a) temporal evolution of trench and plate velocities, (b) the upper-plate tilt as a function of the slab-tip depth, (c) the upper-plate inundation as a function of the slab-tip depth, and (d) the effective viscosity. Red-grey dashed lines indicate the mean values before and after slab-transition zone interaction and black dots indicate the current time step shown in (d). 